\title{
EFFECT OF HALL CURRENTS AND RADIATION ABSORPTION ON UNSTEADY HYDRO MAGNETIC CHEMICALLY REACTING MICRO POLAR FLUID THROUGH A POROUS MEDIUM IN A ROTATING SYSTEM WITH VARIABLE SUCTION
}

\author{
Dr.R. Siva Gopal ${ }^{1}$, Dr.V.Suresh Babu ${ }^{2}$ \\ ${ }^{1}$ Department of Mathematics, S.K.University, Anantapuramu-515003, A.P., India \\ 2 professor in Mathematics, Dept of H\&S,G.Pullaiah college of Engineering \& \\ Technology,Kurnool,A.P.,India
}

\begin{abstract}
:
We investigate the effect of combined influence of Hall currents and radiation absorption on unsteady hydro magnetic chemically reacting micropolar fluid through a porous medium in a rotating system with variable suction. The dimensionless governing equations for this investigation are solved by using perturbation technique. The effect of various dimensionless parameters entering the problem on the velocity, temperature, concentration and microrotation profiles across the boundary layer is presented through graphs. Also the result of the Skin friction, couple stress, the rate of heat and mass transfer at the wall are discussed for different parametric variations.
\end{abstract}

KEYWORDS: Heat and Mass Transfer, Magnetic parameter, Hall parameter, Rotation Parameter, MHD.

\section{INTRODUCTION}

The micropolar fluids are fluids with microstructure and asymmetrical stress tensor. Physically, they represent fluids consisting of randomly oriented particles suspended in a viscous medium. These types of fluids are used in analyzing liquid crystals, animal blood, fluid flowing in brain, exotic lubricants, the flow of colloidal suspension, paints, turbulent shear flows and body fluids after mathematically and industrially[1,2].

The theory of micropolar fluids was proposed by Eringen [8] this theory displays the effect of local rotary inertia and couple stress. The micropolar fluid which contains micro constituents and can undergo rotation. The comprehensive literature on micro polar fluids, thermo micropolar fluids and their applications in engineering and technology were presented by Eringen [7].The theory of rotating fluids has been developed by Greenspan [10] is highly important due to its occurrence in various natural phenomena and for its applications in various technological situations, which are directly governed by the action of Carioles force.

The broad subjects of oceanography, meteorology, atmospheric science and limnology all contain some important and essential features of rotating fluids. The oscillatory boundary layer flow with constant heat source in the case of MHD free convection currents and mass transfer has been considered by Rahman and Sattar [21]. Khonsari and Brewe [15], have examined the effect of viscous dissipation on the lubrication characteristics of micropolar fluids. Seddeek [27] studied the flow of a magneto-micro polar fluid past a continuously moving plate. Gibben [11] considered the MHD boundary layer flow over a semi-infinite plate with an aligned magnetic field in the presence of pressure gradient. He has obtained solutions for large and small magnetic Prandtl numbers using the method of matched asymptotic expansion. The MHD principle also finds its application in Medicine and Biology. Application in biomedical engineering includes cardiac MRI, ECG etc. Kim and Lee [16] analytically studied an MHD oscillatory flow of a micropolar fluid over a vertical porous plate. Rapits [24] presented the flow of a micropolar fluid past a continuous moving plate by the presence of 
DOI: https://dx.doi.org/10.26808/rs.ca.i8v1.05 International Journal of Computer Application (2250-1797)

Issue 8 Volume 1, January- February 2018

radiation. El-Arabawy [6] analyzed the effect of suction/injection on the flow of a micro polar fluid past continuously moving plate in the presence of radiation.

MHD in its present form is due to the pioneer contribution of several notable authors like Alfven [1], Shercliff [28], Ferraro and Plumpton [9] and Crammer and Pai [4]. It was emphasized that when the strength of the magnetic field is sufficiently large, ohm's law needs to be modified to include Hall current.

Cogley et al. [3] showed that in the optically thin limit, the fluid does not absorb its own emitted radiation but the fluid does absorb radiation emitted by the boundaries. Ibrahim et al. [13] discussed the case of mixed convection flow of a micro polar fluid past a semi infinite steady moving porous plate with varying suction velocity normal to the plate in presence of thermal radiation and viscous dissipation. Rahman and Sattar [22] studied transient convective flow of micro polar fluid past a continuous moving porous plate in the presence of radiation. The effect of the chemical reaction and radiation absorption on the unsteady MHD free convection flow past a semi-infinite vertical permeable moving plate with heat source and suction has been studied by Ibrahim et al. [13]. Rahman and Sultana [22] examined radiative heat flux with variable heat flux in a porous medium. Recently Bakr [2] presented an analysis on MHD free convection and mass transfer adjacent to moving vertical plate for micropolar fluid in a rotating frame of reference in presence of heat generation/absorption and a chemical reaction. Radhakrishnamachary [20] analyzed the flow of micropolar fluid through a constricted channel. Rees and Pop [25] discussed the free convection boundary layer flow of a micropolar fluid from a vertical flat plate. Sharma and Gupta [29] studied the effects of medium permeability on thermal convection in micropolar fluids. Muthu et al. [18] studied peristaltic motion of micropolar fluid in circular cylindrical tubes. Srinivasacharya et al. [26] analyzed the unsteady stokes flow of micropolar fluid between two parallel porous plates. Muthuraj and Srinivas [19] investigated fully developed MHD flow of a micropolar and viscous fluids in a vertical porous space using Ham. Kim [16] investigated the effects of heat and mass transfer in the MHD micropolar fluid flow past a vertical moving plate.

The simultaneous effects of heat and mass transfer with chemical reaction are of great importance to engineers and scientists because of its occurrence in many branches of science and engineering. Recently, Das [5] has studied the effect of first order chemical reaction in thermal radiation hydro magnetic free convective heat and mass transfer flow of a micropolar fluid bounded by the semi infinite porous plate with constant heat and source in a rotating frame of reference. Hayat et al. [12] discussed the boundary value problem for oscillating rotating flows of MHD Oldroyd - B fluid in a porous space. Suresh et al [32] have discussed the effect of Hall currents and thermodiffusion on convective heat and mass transfer flow in a rotation fluid with heat sources. Sulochana et al [31] have investigated combined influence of Hall effects and radiation on convective heat and mass transfer flow in a rotating system with heat sources. Satyanarayana et al. [26] have discussed the influence of Hall currents and radiation absorption on convective heat and mass transfer flow of a micro polar fluid with heat sources with constant suction.

\section{FORMULATION OF THE PROBLEM}

We consider the unsteady two dimensional flow of an incompressible, viscous, electrically conducting micro polar fluid through a porous medium past a semi-infinite vertical permeable moving plate embedded in a uniform porous medium and subjected to a constant transverse magnetic field $\mathrm{B}_{0}$ in the presence of thermal and concentration buoyancy effects with thermal radiation. It is assumed that there is no applied voltage which implies the absence of an electric field. The flow is assumed to be in the $\mathrm{x}$-direction which is taken along the plate in the upward direction and z-direction is normal to it. Also it is assumed that the whole system rotates with a constant frame $\Omega$ in a micro polar fluid about z-axis. The fluid is assumed to be gray, absorbing-emitting but not scattering medium. The radiation heat flux in $\mathrm{x}$-direction is considered negligible in comparison to the $\mathrm{z}$-direction. Due to the semi-infinite plate surface assumption, further more the flow variables are functions $\mathrm{z}$ and time only. 
When the strength of the magnetic field is very large we include the Hall current so that the generalized Ohm's law is modified to

$$
\bar{J}+\omega_{e} \tau_{e} \bar{J} x \bar{H}=\sigma\left(\bar{E}+\mu_{e} \bar{q} x \bar{H}\right)
$$

where $\mathrm{q}$ is the velocity vector. $\mathrm{H}$ is the magnetic field intensity vector. $\mathrm{E}$ is the electric field; $\mathrm{J}$ is the current density vector, $\omega_{e}$ is the cyclotron frequency, $\tau_{e}$ is the electron collision time, $\sigma$ is the fluid conductivity and $\mu_{e}$ is the magnetic permeability. Neglecting the electron pressure gradient, ion-slip and thermo-electric effects and assuming the electric field $\mathrm{E}=0$, equation (1) reduces

$$
\begin{aligned}
& j_{x}-m H_{0} J_{y}=-\sigma \mu_{e} H_{0} v \\
& J_{y}+m H_{0} J_{x}=\sigma \mu_{e} H_{0} u
\end{aligned}
$$

where $\mathrm{m}=\omega_{e} \tau_{e}$ is the Hall parameter

$$
\begin{gathered}
u_{t}-w_{o}\left(1-\varepsilon A e^{n t}\right) u_{z}-2 \Omega v=\left(v+v_{r}\right) u_{y y}-\left(\frac{\mu}{k}\right) u+\frac{\sigma \mu_{e}^{2} H_{0}^{2}}{1+m^{2} H_{0}^{2}}\left(u+m H_{0} v\right) J_{y}+ \\
+\beta g\left(T-T_{\infty}\right)+\beta^{\bullet} g\left(C-C_{\infty}\right)-v_{r} \omega_{2, z} \\
v_{t}-w_{o}\left(1-\varepsilon A e^{n t}\right) v_{z}+2 \Omega u=\left(v+v_{r}\right) v_{y y}-\left(\frac{\mu}{k}\right) v-\frac{\sigma \mu_{e}^{2} H_{0}^{2}}{1+m^{2} H_{0}^{2}}\left(m H_{0} u-v\right) J_{x}+v_{r} \omega_{1, z} \\
\frac{\partial \omega_{1}}{\partial t}-w_{0}\left(1+\varepsilon e^{n t}\right) \frac{\partial \omega_{1}}{\partial z}=\frac{\mathrm{A}}{\rho j} \frac{\partial^{2} \omega_{1}}{\partial z^{2}} \\
\frac{\partial \omega_{2}}{\partial t}-w_{0}\left(1+\varepsilon e^{n t}\right) \frac{\partial \omega_{2}}{\partial z}=\frac{\mathrm{A}}{\rho j} \frac{\partial^{2} \omega_{2}}{\partial z^{2}}
\end{gathered}
$$

Solving (2) and (3) we obtain $\mathrm{J}_{\mathrm{x}}$ and $\mathrm{J}_{\mathrm{y}}$ using the equations (4) and (5) then the governing equations are

The Energy equation

$$
\rho C_{p}\left(\frac{\partial T}{\partial t}-w_{0}\left(1+\varepsilon e^{n t}\right) \frac{\partial T}{\partial z}\right)=k_{f} \frac{\partial^{2} T}{\partial z^{2}}+Q\left(T_{e}-T\right)+Q_{1}^{\prime}\left(C-C_{\infty}\right)
$$

The Diffusion equation

$$
\frac{\partial C}{\partial t}-w_{o}\left(1+\varepsilon e^{n t}\right) \frac{\partial C}{\partial z}=D_{1} \frac{\partial^{2} C}{\partial z^{2}}-k_{c} c
$$

The Equation of state

$$
\rho-\rho_{0}=-\beta\left(T-T_{o}\right)-\beta^{\bullet}\left(C-C_{o}\right)
$$

where $\mathrm{T}, \mathrm{C}$ are the temperature and concentration in the fluid. $\mathrm{k}$ is the porous permeability, $\mathrm{k}_{\mathrm{f}}$ is the thermal conductivity, $\mathrm{Cp}$ is the specific heat constant pressure, $\mathrm{D}_{1}$ is molecular diffusivity, $\beta$ is the coefficient of thermal expansion, $\beta^{\bullet}$ is the coefficient of volume expansion, $\mathrm{Q}$ is the strength of the heat source, $Q_{1}^{\prime}$ is the radiation absorption coefficient. $\mathrm{q}_{\mathrm{r}}$ is the radiative heat flux.

By Rosseland approximation, the radiative heat flux is given by

$$
q_{r}=-\frac{4 \sigma^{\bullet}}{3 \beta_{r}} \frac{\partial\left(T^{\prime 4}\right)}{\partial z}
$$

Expanding $T^{\prime 4}$ about $\mathrm{T}_{\mathrm{e}}$ by Taylor expansion and neglecting the higher order terms we get

$$
T^{\prime 4} \cong 4 T T_{e}^{3}-3 T_{e}^{4}
$$

where $\sigma^{\bullet}$ is the Stefan-Boltzmann constant and $\beta_{r}$ is the mean absorption coefficient. Substituting (11) and (12) in (8), we obtain 


$$
\rho C_{p}\left(\frac{\partial T}{\partial t}-w_{0}\left(1+\varepsilon e^{n t}\right) \frac{\partial T}{\partial z}\right)=k_{f} \frac{\partial^{2} T}{\partial z^{2}}+Q\left(T_{\infty}-T\right)+Q_{1}^{\prime}\left(C-C_{\infty}\right)
$$

The boundary conditions are

$$
\begin{aligned}
& u=v=0, \omega_{1}=\omega_{2}=0, T=T_{\infty}, C=C_{\infty} \quad \text { for } t \leq 0 \\
& u=U_{r}(1+\varepsilon \exp (n t)), v=0, \omega_{1}=-0.5 \frac{\partial v}{\partial z}, \omega_{2}=0.5 \frac{\partial u}{\partial z}, \\
& T=T_{w}+\varepsilon\left(T_{w}-T_{\infty}\right) e^{n t}, C=C_{w}+\varepsilon\left(C_{w}-C_{\infty}\right) e^{n t} \text { on } z=0 \\
& u=v=0, \omega_{1}=0, \omega_{2}=0, T=T_{\infty}, C=C_{\infty} \text { as } z \rightarrow \infty, t>0
\end{aligned}
$$

on introducing the non-dimensional variables

$$
\begin{aligned}
& z^{\prime}=\frac{z U_{r}}{v}, t^{\prime}=\frac{t U_{r}^{2}}{v}, u^{\prime}=\frac{u}{U_{r}}, v^{\prime}=\frac{v}{U_{r}}, n^{\prime}=\frac{n v}{U_{r}^{2}}, \omega_{1}^{\prime}=\frac{\omega_{1} v}{U_{r}^{2}}, \omega_{2}^{\prime}=\frac{\omega_{2} v}{U_{r}^{2}}, \\
& \theta=\frac{T-T_{\infty}}{T_{w}-T_{\infty}}, C^{\prime}=\frac{C-C_{\infty}}{C_{w}-C_{\infty}}
\end{aligned}
$$

The equations (4)-(7), (9) and (13) reduces to

$$
\begin{gathered}
u_{t}-S\left(1+\varepsilon e^{n t}\right) u_{z}-R v=(1+\Delta) u_{y y}-D^{-1} u-\frac{M^{2}}{1+m^{2}}(u+m w)+ \\
+G(\theta+N C)-\omega_{2, z} \\
v_{t}-S\left(1+\varepsilon e^{n t}\right) v_{z}+R u=(1+\Delta) v_{y y}-D^{-1} v+\frac{M^{2}}{1+m^{2}}(m u-w)+\omega_{1, z} \\
\frac{\partial \omega_{1}}{\partial t}-S\left(1+\varepsilon e^{n t}\right) \frac{\partial \omega_{1}}{\partial z}=\lambda \frac{\partial^{2} \omega_{1}}{\partial z^{2}} \\
\frac{\partial \omega_{2}}{\partial t}-S\left(1+\varepsilon e^{n t}\right) \frac{\partial \omega_{2}}{\partial z}=\lambda \frac{\partial^{2} \omega_{2}}{\partial z^{2}} \\
\left(\theta_{t}-S\left(1+\varepsilon e^{n t}\right) \theta_{z}\right)=\frac{\left(3 N_{1}+4\right)}{3 N_{1} P_{r}}\left(\theta_{z z}\right)-\alpha \theta+Q_{1} C \\
\left(C_{t}-S\left(1+\varepsilon e^{n t}\right) C_{z}\right)=\frac{1}{S c} \frac{\partial^{2} C}{\partial z^{2}}-k c
\end{gathered}
$$

where

$$
R=\frac{2 \Omega v}{U_{r}^{2}} \text { Rotation parameter, } M=\frac{B_{0}}{U_{r}} \sqrt{\sigma v / \rho} \text { Magnetic parameter }
$$
$D^{-1}=\frac{v}{k}$ Inverse Darcy parameter, $\operatorname{Pr}=\frac{\mu C_{p}}{k_{f}} \quad$ Prandtl number $Q_{1}=\frac{Q_{1}^{\prime}\left(C_{w}-C_{\infty}\right) v^{2}}{k_{f}\left(T_{w}-T_{\infty}\right) U_{r}^{2}} \quad$ Radiation absorption parameter $G=\frac{\beta g v\left(T_{w}-T_{\infty}\right)}{U_{r}^{3}} \quad$ Grashof number, $N=\frac{\beta^{\bullet}\left(C_{w}-C_{\infty}\right)}{\beta\left(T-T_{\infty}\right)}$ Buoyancy ratio $S=\frac{w_{o}}{U_{r}} \quad$ Suction parameter, $N_{1}=\frac{\beta_{R} k_{f}}{4 \sigma^{\bullet} T_{\infty}^{3}} \quad$ Radiation parameter, $m=\omega_{e} l_{e} \quad$ Hall parameter, $\lambda=\frac{\Delta}{\mu j} \quad$ Micro rotation parameter 
$\Delta=\frac{v_{r}}{v} \quad$ Viscosity ratio parameter

The non-dimensional boundary conditions are

$$
\begin{aligned}
& u=v=0, \omega_{1}=\omega_{2}=0, \theta=0, C=0 \quad \text { for } t \leq 0 \\
& u=(1+\varepsilon \exp (n t)), v=0, \omega_{1}=-0.5 \frac{\partial v}{\partial z}, \omega_{2}=0.5 \frac{\partial u}{\partial z}, \\
& \theta=1+\varepsilon e^{n t}, C=1+\varepsilon e^{n t} \quad \text { on } z=0 \\
& u=v=0, \omega_{1}=0, \omega_{2}=0, \theta=0, C=0 a s \quad z \rightarrow \infty, t>0
\end{aligned}
$$

We now simplify the equations (15)-(20) by putting the fluid velocity and angular velocity in the complex form as $q=u+i v, \quad \omega=\omega_{1}+i \omega_{2}$ and we obtain

$$
\begin{gathered}
q_{t}-S\left(1+\varepsilon e^{n t}\right) q_{z}+(i R) q=(1+\Delta) q_{y y}-D^{-1} q-\frac{M^{2}(1-i m)}{1+m^{2}} q+i \omega_{z} \\
+G(\theta+N C) \\
\frac{\partial \omega}{\partial t}-S\left(1+\varepsilon e^{n t}\right) \frac{\partial \omega}{\partial z}=\lambda \frac{\partial^{2} \omega}{\partial z^{2}} \\
\left(\theta_{t}-S\left(1+\varepsilon e^{n t}\right) \theta_{z}=\frac{\left(3 N_{1}+4\right)}{3 N_{1} P_{r}}\left(\theta_{z z}\right)-\alpha \theta+Q_{1} C\right. \\
\left(C_{t}-S\left(1+\varepsilon e^{n t}\right) C_{z}=\frac{1}{S c} \frac{\partial^{2} C}{\partial z^{2}}-k c\right.
\end{gathered}
$$

The corresponding boundary conditions are

$$
\begin{aligned}
& q=0, \omega=0, \theta=0, C=0 \text { for } \quad t \leq 0 \\
& q=1+\varepsilon e^{n t}, \omega=0.5 \frac{\partial q}{\partial z} \quad \theta=1+\varepsilon e^{n t}, C=1+\varepsilon e^{n t} \quad \text { at } z=0 \\
& q=0, \omega=0, \theta=0, C=0 \quad \text { as } z \rightarrow \infty \quad \text { for } t>0
\end{aligned}
$$

\section{SOLUTION OF THE PROBLEM}

To find the analytical solutions of the above system of partial differential equations (23)-(26) in the neighborhood of the plate under the above boundary conditions (27), we express $\mathrm{q}, \omega, \theta$ and $\mathrm{C}$ as

$$
\begin{aligned}
& q=q_{0}+\varepsilon e^{n t} q_{1} \\
& \omega=\omega_{0}+\varepsilon e^{n t} \omega_{1} \\
& \theta=\theta_{o}+\varepsilon e^{n t} \theta_{1} \\
& C=C_{o}+\varepsilon e^{n t} C_{1}
\end{aligned}
$$

Invoking the above expansions into the equations (23)-(26) and equating the steady and transient parts and neglecting the higher order terms of $\mathrm{O}\left(\varepsilon^{2}\right)$, we obtain the following set of equations to the $0^{\text {th }}$ order are

$$
\begin{aligned}
& -s \frac{\partial q_{0}}{\partial z}=(1+\Delta) \frac{\partial^{2} q_{0}}{\partial z^{2}}-\left(M_{1}^{2}+i R\right) q_{0}+i \frac{\partial \omega_{0}}{\partial z}+G\left(\theta_{0}+N C_{0}\right) \\
& \lambda \frac{\partial^{2} \omega_{0}}{\partial z^{2}}+S \frac{\partial \omega_{0}}{\partial z}=0
\end{aligned}
$$




$$
\begin{aligned}
& -S \frac{\partial \theta_{0}}{\partial z}=\frac{\left(3 N_{1}+4\right)}{3 N_{1} P_{r}} \frac{\partial^{2} \theta_{0}}{\partial z^{2}}-\alpha \theta_{0}+Q_{1} C_{o} \\
& -S \frac{\partial C_{0}}{\partial z}=\frac{1}{S c} \frac{\partial^{2} C_{0}}{\partial z^{2}}-k C_{0}
\end{aligned}
$$

and to the first order are

$$
\begin{aligned}
& (1+\Delta) \frac{\partial^{2} q_{0}}{\partial z^{2}}+S \frac{\partial q_{1}}{\partial z}-\left(M_{1}^{2}+n+i R\right) q_{1}+i \frac{\partial \omega_{1}}{\partial z}=-S \frac{\partial q_{0}}{\partial z}- \\
& -G\left(\theta_{1}+N C_{1}\right) \\
& \lambda \frac{\partial^{2} \omega_{1}}{\partial z^{2}}+S \frac{\partial \omega_{1}}{\partial z}=0 \\
& \frac{\partial^{2} \theta_{1}}{\partial z^{2}}+S P_{r} \frac{\partial \theta_{1}}{\partial z}-\left(\alpha_{2}+n\right) \theta_{1}=-S \frac{\partial \theta_{0}}{\partial z}-Q_{1} C_{1} \\
& \frac{\partial^{2} C_{1}}{\partial z^{2}}+S S c \frac{\partial C_{1}}{\partial z}-(k S c+n) C_{1}=0
\end{aligned}
$$

The corresponding boundary conditions can be written as

$$
\begin{gathered}
q_{o}=1, q_{1}=1, \omega_{0}=0.5 \frac{\partial q_{o}}{\partial z}, \omega_{1}=0.5 \frac{\partial q_{1}}{\partial z} \\
\theta_{o}=1, \theta_{1}=1, C_{o}=1, C_{1}=1 \text { at } z=0 \\
q_{o}=q_{1}=0, \omega_{o}=\omega_{1}=0, \theta_{o}=\theta_{1}=0 \\
C_{o}=C_{1}=0 \text { as } z \rightarrow \infty \quad \text { fort }>0
\end{gathered}
$$

Solving equations (29)-(36) under the boundary conditions (37) we obtain the expressions for the translational velocity, micro-rotation, temperature and concentration as

$$
\begin{aligned}
& C_{o}=\exp \left(-m_{1} y\right) \\
& \theta_{o}=\left(1-a_{2}\right) \exp \left(-m_{2} y\right)+a_{1} \exp \left(-m_{1} y\right) \\
& \omega_{0}=a_{3} \exp \left(-m_{3} y\right) \\
& \left.\left.q_{0}=a_{7} \exp \left(-m_{4} y\right)+a_{4} \exp \left(-m_{2} y\right)\right)+a_{5} \exp \left(-m_{1} y\right)\right)+a_{6} a_{3} \exp \left(-m_{3} y\right) \\
& C_{1}=\left(1-a_{9}\right) \exp \left(-m_{5} y\right)+a_{9} \exp \left(-m_{1} y\right) \\
& \theta_{1}=a_{13} \exp \left(-m_{6} y\right)+a_{11} \exp \left(-m_{5} y\right)+a_{12} \exp \left(-m_{1} y\right) \\
& \omega_{1}=a_{14} \exp \left(-m_{7} y\right) \\
& q_{1}=a_{19} \exp \left(-m_{8} y\right)+a_{16} \exp \left(-m_{5} y\right)+a_{17} \exp \left(-m_{1} y\right)+a_{18} a_{14} \exp \left(-m_{7} y\right)
\end{aligned}
$$

\section{RATE OF HEAT and MASS TRANSFER:}

The rate of heat transfer (Nusselt Number) at $\mathrm{z}=0$ is given by

$$
N u_{z=0}=\left(\frac{\partial \theta_{0}}{\partial z}+\varepsilon e^{n t} \frac{\partial \theta_{1}}{\partial z}\right)_{z=0}=a_{22}+\varepsilon e^{n t} a_{23}
$$

The rate of mass transfer (Sherwood Number) at $\mathrm{z}=0$ is given by

$$
S h_{y=0}=\left(\frac{\partial C_{0}}{\partial z}+\varepsilon e^{n t} \frac{\partial C_{1}}{\partial z}\right)_{z=0}=-m_{1}+\varepsilon e^{n t} a_{24}
$$

The couple stress coefficient at $\mathrm{z}=0$ is given by

$$
C_{w}=\left(\frac{\partial \omega_{0}}{\partial z}+\varepsilon e^{n t} \frac{\partial \omega_{1}}{\partial z}\right)_{z=0}=-a_{3} m_{3}-\varepsilon e^{n t} a_{14} m_{7}
$$




$$
\begin{aligned}
& M_{1}^{2}=\frac{M^{2}(1-i m)}{1+m^{2}}+D^{-1} \\
& M_{1}^{2}=\frac{M^{2}(1-2 i m)}{1+m^{2}}+D^{-1} \\
& m_{1}=\left(S S c+\sqrt{S^{2} S c^{2}+4(K S c)}\right) / 2, \quad m_{2}=\left(S P_{1}+\sqrt{S^{2} P_{1}^{2}+4 \alpha_{1}}\right) / 2, \\
& m_{3}=\frac{S}{\lambda}, m_{4}=\left(S+\sqrt{S^{2}+4\left(M_{1}^{2}+i R\right.}\right) / 2(1+\Delta) \\
& m_{5}=\left(S S c+\sqrt{S^{2} S c^{2}+4(k S c+n)}\right) / 2, \\
& \left.m_{6}=\left(S P_{1}+\sqrt{S^{2} P_{1}^{2}+4\left(\alpha_{1}\right.}+n\right)\right) / 2, m_{7}=\frac{S+\sqrt{S^{2}+4 n}}{2 \lambda} \\
& m_{8}=\left(S+\sqrt{S^{2}+4\left(M_{1}^{2}+i R\right.}+n\right) / 2(1+\Delta) \\
& a_{1}=-\frac{Q_{1}}{\left(m_{1}^{2}-S P_{1} m_{1}-\alpha_{1}\right)}, a_{2}=1-a_{1}, \\
& a_{4}=-G\left(1-a_{1}\right) /(1+\Delta) m_{2}^{2}-S m_{2}-\left(M_{1}^{2}+i R\right) \\
& a_{5}=-G\left(a_{1}+N\right) /\left((1+\Delta) m_{1}^{2}-S m_{1}-\left(M_{1}^{2}+i R\right)\right. \\
& a_{6}=-i a_{3} m_{3} /\left((1+\Delta) m_{3}^{2}-S m_{3}-\left(M_{1}^{2}+i R\right), \quad a_{7}=1-a_{4}-a_{5}-a_{6} a_{3}\right. \\
& a_{3}=\frac{0.5\left(a_{4} m_{2}+a_{5} m_{1}-\left(a_{4}+a_{5}+1\right) m_{4}\right)}{\left(1+0.5 a_{7}\left(m_{4}+m_{3}\right)\right.}, a_{9}=\frac{S S c m_{1}}{m_{1}^{2}-S S_{c} m_{1}-\left(k S c+n_{1}\right)}, a_{10}=1+a_{9} \\
& a_{11}=-\frac{Q_{1}\left(1-a_{9}\right)}{\left(m_{5}^{2}-S P_{1} m_{5}-\left(\alpha_{1}+n\right)\right)}, a_{12}=-\frac{Q_{1} a_{9}}{\left(m_{5}^{2}-S P_{1} m_{5}-\left(\alpha_{1}+n\right)\right)} \\
& a_{13}=1-a_{11}-a_{12}, a_{15}=-\frac{G a_{13}}{(1+\Delta) m_{6}^{2}-S m_{6}-\left(M_{1}^{2}+i R+n\right)} \\
& a_{16}=-\frac{G\left(a_{11}+N a_{10}\right)}{(1+\Delta) m_{5}^{2}-S m_{5}-\left(M_{1}^{2}+i R+n\right)}, a_{17}=-\frac{G\left(N a_{9}+a_{12}\right)}{(1+\Delta) m_{1}^{2}-S m_{1}-\left(M_{1}^{2}+i R+n\right)} \\
& a_{18}=-\frac{i m_{7} a_{14}}{(1+\Delta) m_{7}^{2}-S m_{7}-\left(M_{1}^{2}+i R+n\right)}, \quad a_{19}=1-a_{15}-a_{16}-a_{17}-a_{18} a_{14} \\
& a_{20}=-a_{7} m_{4}-a_{4} m_{2}-a_{5} m_{1}-a_{6} a_{3} m_{3}, a_{21}=-a_{19} m_{8}-a_{15} m_{6}-a_{16} m_{5}-a_{17} m_{1}-a_{18} a_{14} m_{7} \\
& a_{22}=+\left(a_{9}-1\right) m_{2}-a_{1} m_{1}, a_{23}=-a_{13} m_{6}-a_{11} m_{5}-a_{12} m_{1}, a_{24}=m_{5}\left(a_{9}-1\right)-a_{9} m_{1}
\end{aligned}
$$

\section{RESULTS AND DISCUSSION}

We analyze the combined effect of Hall currents and radiation absorption on unsteady hydro magnetic chemically reacting micropolar fluid through a porous medium in a rotating system with variable suction. The velocity, temperature, concentration and the micro rotation are analyzed for different variations.

Figs (1- 8), represents the primary velocity u with variations in $M, D^{-1}, m, G, R, S, Q_{1}, N_{1}$ and $\lambda$. It is found that the primary velocity enhances with increase in $|\mathrm{G}|$ and Rotation parameter R Figs (1 \& 6). Fig.2 represents the variation of $u$ with magnetic parameter $M$ and Hall parameter $m$. It can be seen from the profiles that the primary velocity reduces in magnitude with increase in $\mathrm{M}$. This reduction in can be attributed to the fact that the magnetic field provides a resisting type of force 
DOI: https://dx.doi.org/10.26808/rs.ca.i8v1.05 International Journal of Computer Application (2250-1797)

known as the Lorentz force. This force tends to lessen the motion of the fluid and as a consequence the velocity reduces. It is observed that the velocity along sheet decreases with $\mathrm{M}$ accompanied by a reduction in the thickness of the boundary layer. An increase in Hall parameters $m$ enhances $|u|$. This increase is due to the fact that as $m$ increases the Lorentz force opposes the flow and leads to the degeneration of the fluid motion. Fig. 3 shows the variation of $u$ with inverse Darcy parameter $\left(\mathrm{D}^{-1}\right)$.It is seen that increasing values of $\mathrm{D}^{-1}$ reduces the primary velocity owing to the fact that the presence of the porous medium enhances the resistance to the flow resulting in the reduction of the velocity of fluid. Fig.4 shows the variation of $\mathrm{u}$ with Schmidt number $(\mathrm{Sc})$ and radiation absorption parameter $\left(Q_{1}\right)$. We find that an increase in the radiation absorption parameter $\left(Q_{1}\right)$ results in an enhancement of $|\mathrm{u}|$. Also u decreases with Sc. This shows that lesser the molecular diffusivity smaller the magnitude of the primary velocity. The maximum of $u$ is attained at $y=0.8$. The effect of the suction velocity (S) on $\mathrm{u}$ is shown in Fig.5. An increase in $\mathrm{S}$ decreases the magnitude of $\mathrm{u}$ in the boundary layer. Fig.7 represents $\mathrm{u}$ with buoyancy ratio $(\mathrm{N})$. It is observed that when the molecular buoyancy force dominates over the thermal buoyancy force the magnitude of $u$ increase when the buoyancy forces are in the same direction and for the forces acting in opposite directions, it reduces in the flow region. Fig. 8 shows the variation of $\mathrm{u}$ with radiation parameter (N1). It can be seen from profiles that higher radiative heat flux larger $|\mathrm{u}|$ in the flow region.

The secondary velocity (v) is shown in Figs (9-16) for different parametric values. Fig.9 represents the secondary velocity with Grashof number $(\mathrm{G})$. It can be seen from the profiles that $|\mathrm{v}|$ increases with increase in $|\mathrm{G}|$. With maximum attained at $y=0.8$. Fig. 10 represents $v$ with magnetic parameter $(\mathrm{M})$ and Hall parameter $(\mathrm{m})$. It is observed that the magnitude of $\mathrm{v}$ reduces with increase in $\mathrm{M}$ and $m$ in the flow region.

Fig.11 shows the variation of $\mathrm{v}$ with inverse Darcy parameter $\left(\mathrm{D}^{-1}\right)$. From the figure we notice the secondary velocity exhibits a decreasing tendency with increasing $\mathrm{D}^{-1}$. An increase in the radiation absorption parameter $\left(\mathrm{Q}_{1}\right)$ reduces $|\mathrm{v}|$. This is due to the fact that an increase in $\mathrm{Q}_{1}$ reduces the thickness of the boundary layer which in turn decreases the secondary velocity Fig.12. From fig.13, we find that the magnitude of $\mathrm{v}$ reduces with increase in suction parameter(S), entire flow region. Fig.14 represents $\mathrm{v}$ with rotation parameter $(\mathrm{R})$. It is observed that $|\mathrm{v}|$ exhibits decreasing tendency with increase in $\mathrm{R}$. Fig. 15 shows the variation of $\mathrm{v}$ with buoyancy ratio $(\mathrm{N})$. It is observed from the profiles that when the molecular buoyancy force dominates over the thermal buoyancy force the secondary velocity increase when he buoyancy force $s$ are in the same direction and for the forces acting in opposite directions, it reduces in the flow region. Fig 16 represents $\mathrm{v}$ radiation parameter (N1). It can be seen from profiles that $|\mathrm{v}|$ increases in N1.

The non-dimensional temperature $(\theta)$ is shown in Figs (17-18) for different values of $S, Q_{1}$ and N1. It is found that the non-dimensional temperature is positive in all variations. This shows that the actual temperature is greater than the ambient temperature $\mathrm{T}_{\infty}$. Fig.17 represents $\theta$ with suction parameter (S). It is found that the temperature reduces with decreasing $\mathrm{S}$. The actual temperature enhances with increase in $\mathrm{Q}_{1}$. This is due to the fact increase in $\mathrm{Q}_{1}$ leads to an enhancement in the thickness of the thermal boundary layer and so increase in the actual temperature (Fig.18). From fig.19, we find that the actual temperature enhances with increase in radiation parameter N1.

The non-dimensional concentration distribution (C) is shown in Fig (20) for different value of $\mathrm{S}$. It is found that the non-dimensional concentration is positive for all variations. This shows that the actual concentration is greater than the ambient concentration $\mathrm{C}_{\infty}$. An increase in the suction parameter (S) reduces the concentration in the boundary layer Fig (20).

The micro rotation distribution $(\omega)$ is shown in Figs (21-27) for different values of different parametric values. An increase in the Grashof number (G) increases the micro-rotation (Fig.21). Fig. 22 shows the variation of $\omega$ with magnetic parameter $(\mathrm{M})$ and Hall parameter $\left(\mathrm{n}^{-} \mathrm{TL}_{\mathrm{N}} \ldots\right.$ rotation reduces with $\mathrm{M}$ and $\mathrm{m}$ in the entire boundary layer. From Figs (23), we find rotation reduces with increase in suction parameter $(\mathrm{S})$. 
DOI: https://dx.doi.org/10.26808/rs.ca.i8v1.05 International Journal of Computer Application (2250-1797) Issue 8 Volume 1, January- February 2018

Higher the rotation parameter R larger the micro-rotation (Fig.24). The variation of $\omega$ with inverse Darcy parameter $\left(\mathrm{D}^{-1}\right)$. From the figure (fig.25) we notice the secondary velocity exhibits $\omega$ a decreasing tendency with increasing $\mathrm{D}^{-1}$. From fig.26, we find that the micro rotation distribution enhances with increase in radiation parameter N1. An increase in radiation absorption parameter $\left(\mathrm{Q}_{1}\right)$ leads to a depreciation in $|\omega|$ (Fig. 27).

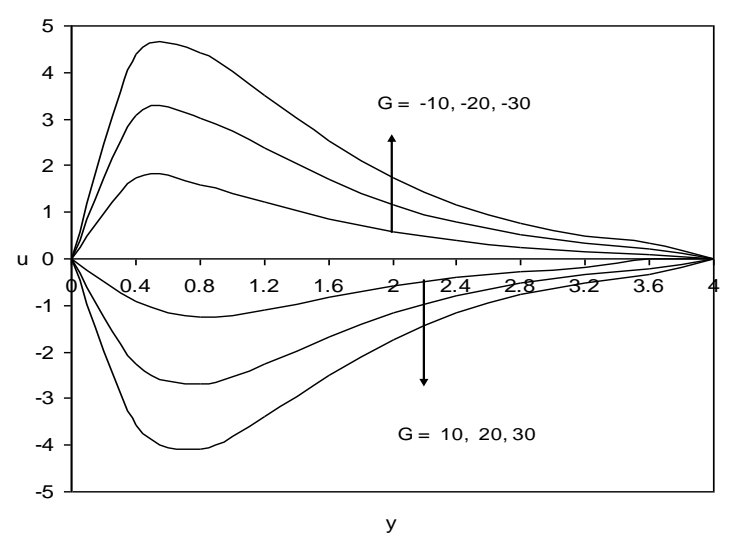

Fig. 1 : Variation of $\mathrm{u}$ with $\mathrm{G}$ $\mathrm{M}=2, \mathrm{~m}=0.5, \mathrm{Q}_{1}=0.5, \mathrm{~S}=0.5$ $\mathrm{R}=0.2, \mathrm{~N}=1, \mathrm{~N} 1=0.5$

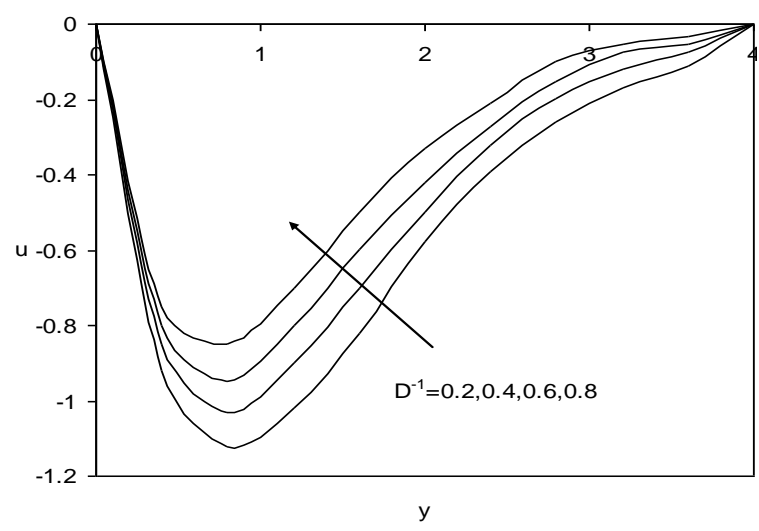

Fig. 3 : Variation of $\mathrm{u}$ with $\mathrm{D}^{-1}$ $\mathrm{M}=2, \mathrm{~m}=0.5, \mathrm{Q}_{1}=0.5, \mathrm{~S}=0.5$, $\mathrm{R}=0.2, \mathrm{~N}=1, \mathrm{~N} 1=0.5$

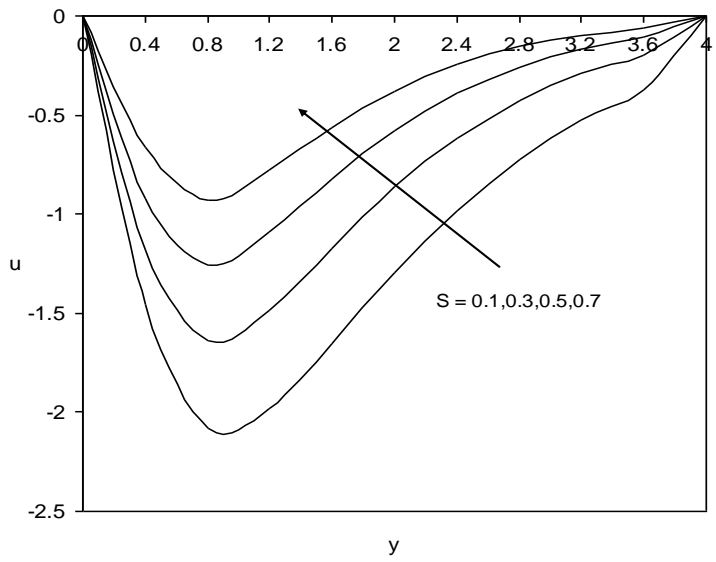

Fig. 5 : Variation of $\mathrm{u}$ with $\mathrm{S}$ $\mathrm{M}=2, \mathrm{~m}=0.5, \mathrm{Q}_{1}=0.5$ $\mathrm{R}=0.2, \mathrm{~N}=1, \mathrm{~N} 1=0.5$

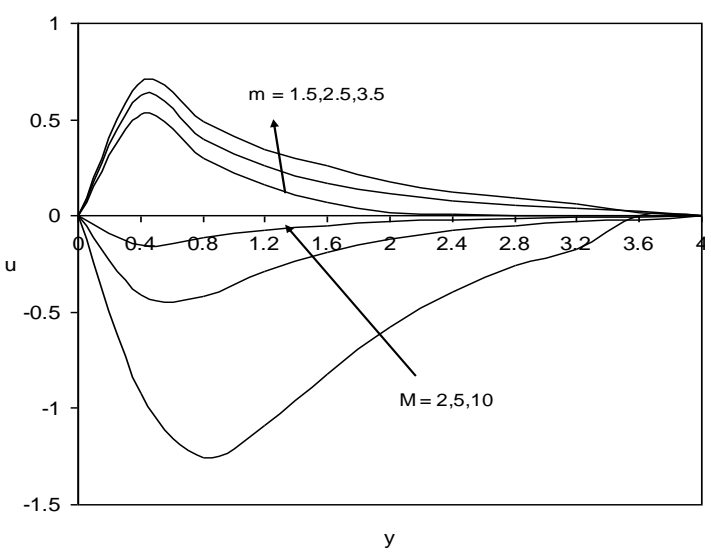

Fig. 2 : Variation of $u$ with $M \& m$ $\mathrm{Q}_{1}=0.5, \mathrm{~S}=0.5, \mathrm{~N} 1=0.5$ $\mathrm{R}=0.2, \mathrm{~N}=1$

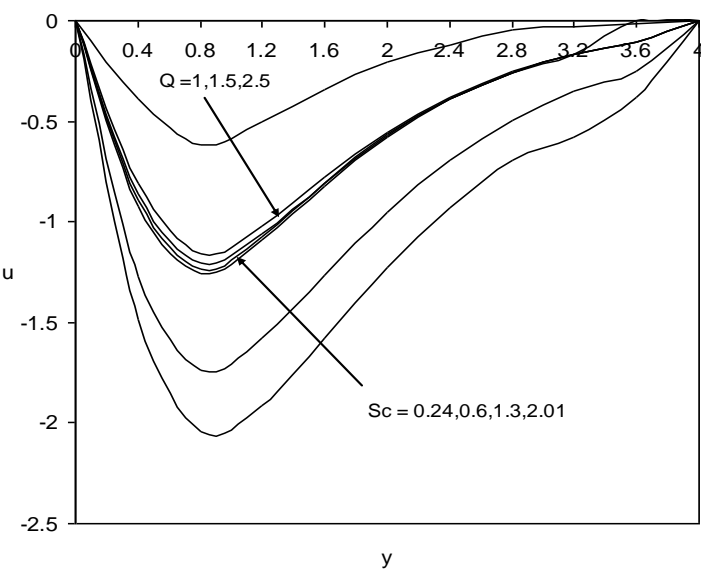

Fig. 4 : Variation of $\mathrm{u}$ with $\mathrm{Sc} \& \mathrm{Q}_{1}$ $\mathrm{M}=2, \mathrm{~m}=0.5, \mathrm{~S}=0.5, \mathrm{~N} 1=0.5$, $\mathrm{R}=0.2, \mathrm{~N}=1$

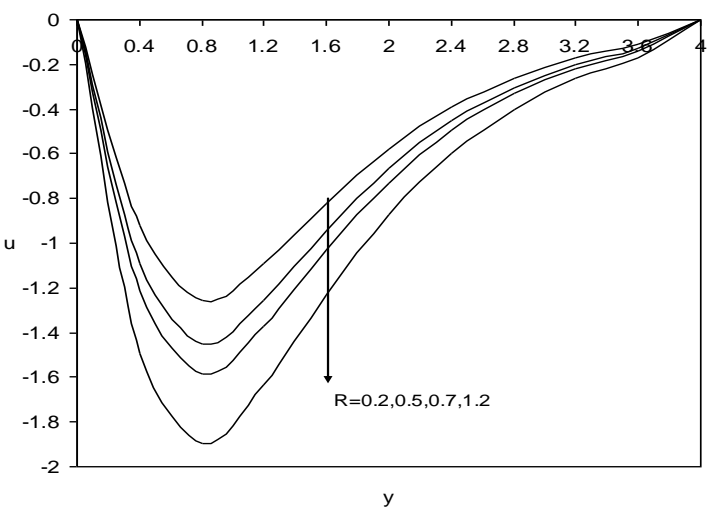

Fig. 6 : Variation of $\mathrm{u}$ with $\mathrm{R}$ $\mathrm{M}=2, \mathrm{~m}=0.5, \mathrm{Q}_{1}=0.5, \mathrm{~S}=0.5$, $\mathrm{N}=1, \mathrm{~N} 1=0.5$ 
DOI: https://dx.doi.org/10.26808/rs.ca.i8v1.05 International Journal of Computer Application (2250-1797)

Issue 8 Volume 1, January- February 2018

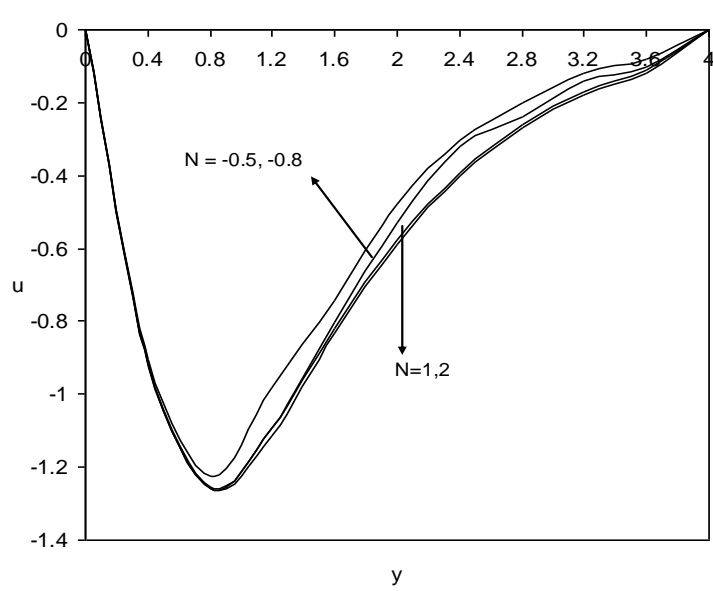

Fig. 7 : Variation of $\mathrm{u}$ with $\mathrm{N}$ $\mathrm{M}=2, \mathrm{~m}=0.5, \mathrm{Q}_{1}=0.5, \mathrm{~S}=0.5$, $\mathrm{R}=0.2, \mathrm{~N} 1=0.5$

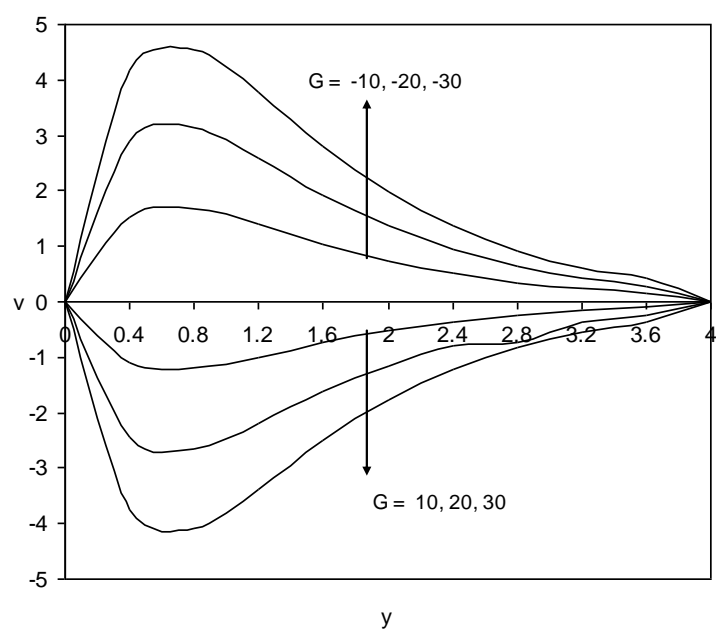

Fig. 9 : Variation of $\mathrm{v}$ with $\mathrm{G}$ $\mathrm{M}=2, \mathrm{~m}=0.5, \mathrm{Q}_{1}=0.5, \mathrm{~S}=0.5$, $\mathrm{R}=0.2, \mathrm{~N}=1, \lambda=0.2, \mathrm{~N} 1=0.5$

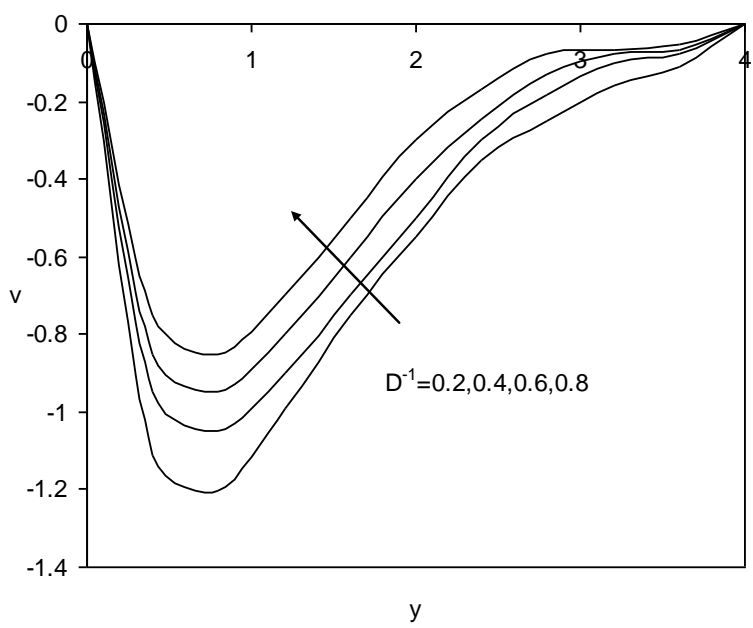

Fig. 11 : Variation of $\mathrm{v}$ with $\mathrm{D}^{-1}$ $\mathrm{M}=2, \mathrm{~m}=0.5, \mathrm{Q}_{1}=0.5, \mathrm{~S}=0.5$, $\mathrm{R}=0.2, \mathrm{~N}=1, \lambda=0.2, \mathrm{~N} 1=0.5$

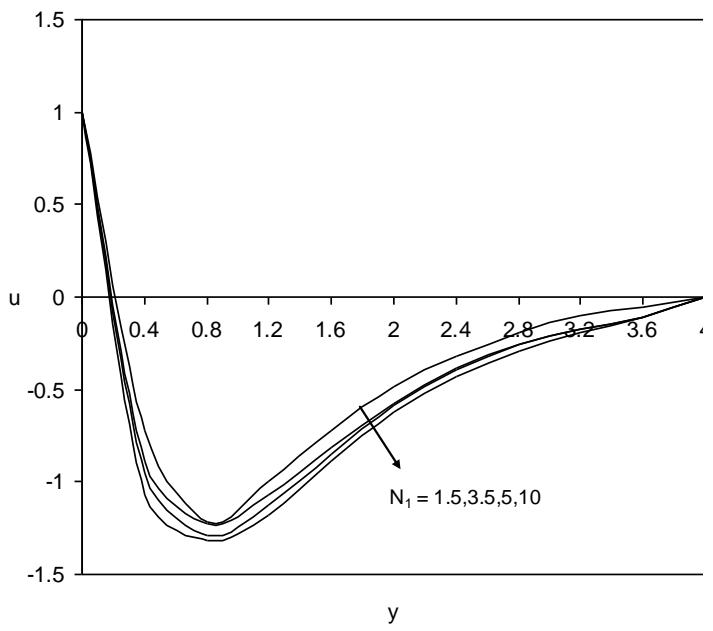

Fig. 8 : Variation of $\mathrm{u}$ with $\mathrm{N}$ $\mathrm{M}=2, \mathrm{~m}=0.5, \mathrm{Q}_{1}=0.5, \mathrm{~S}=0.5, \mathrm{~N}=1$

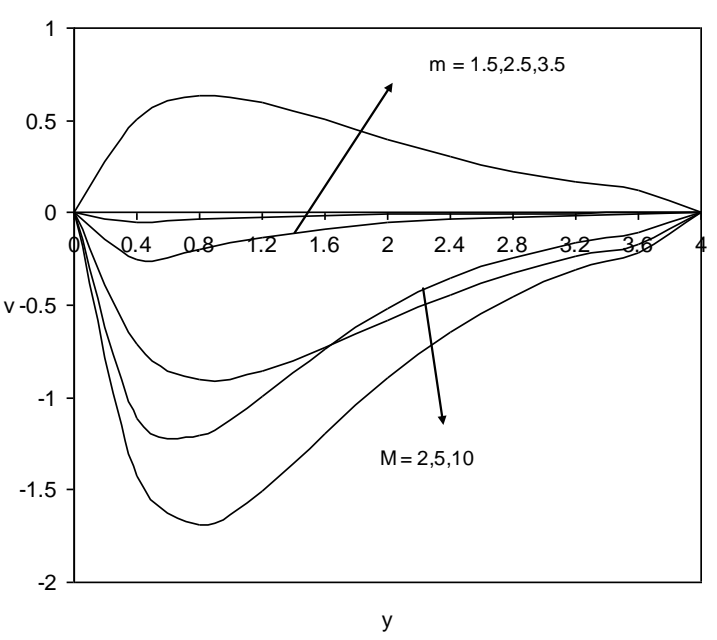

Fig. 10 : Variation of v with $M \& m$ $\mathrm{Q}_{1}=0.5, \mathrm{~S}=0.5$

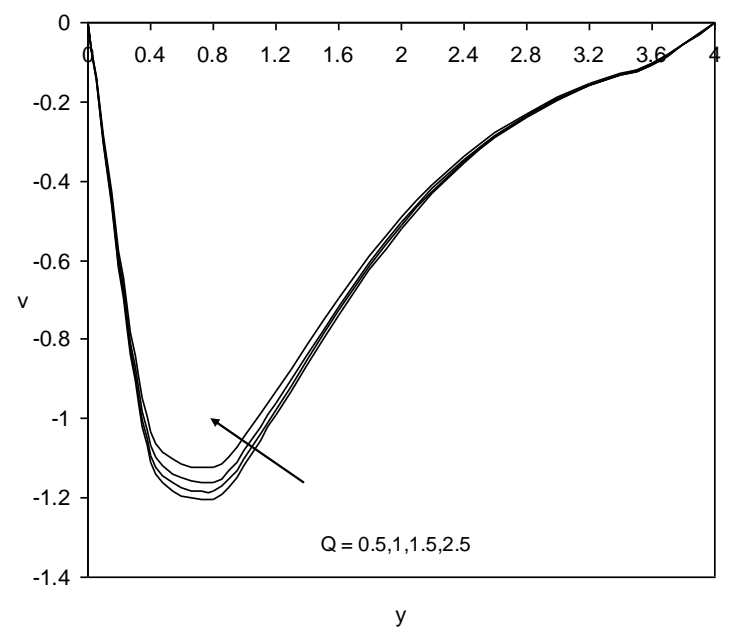

Fig. 12 : Variation of $\mathrm{v}$ with $\mathrm{Q}_{1}$ $\mathrm{M}=2, \mathrm{~m}=0.5, \mathrm{~S}=0.5, \mathrm{~N} 1=0.5$ $\alpha=2, \mathrm{R}=0.2, \mathrm{~N}=1, \lambda=0.2$ 
DOI: https://dx.doi.org/10.26808/rs.ca.i8v1.05 International Journal of Computer Application (2250-1797)

Issue 8 Volume 1, January- February 2018

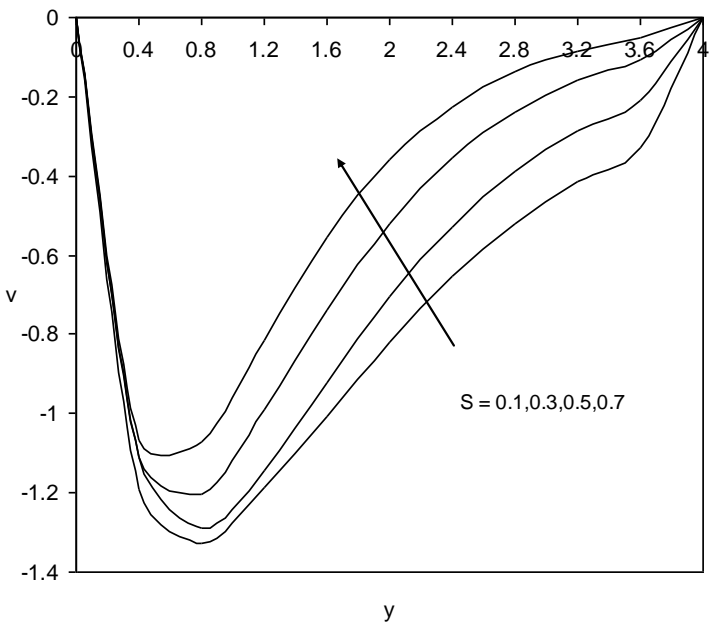

Fig. 13 : Variation of $\mathrm{v}$ with $\mathrm{S}$ $\mathrm{M}=2, \mathrm{~m}=0.5, \mathrm{Q}_{1}=0.5, \mathrm{~N} 1=0.5$ $\mathrm{R}=0.2, \mathrm{~N}=1, \lambda=0.2$

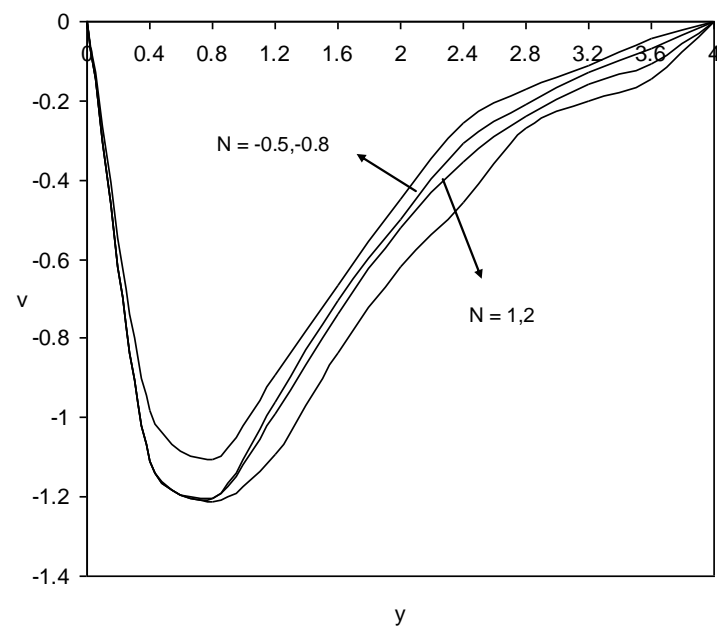

Fig. 15 : Variation of $\mathrm{v}$ with $\mathrm{N}$

$\mathrm{M}=2, \mathrm{~m}=0.5, \mathrm{Sc}=1.3,{ }_{1}=0.5, \mathrm{~S}=0.5$, $\mathrm{R}=0.2, \lambda=0.2, \mathrm{~N} 1=0.5$

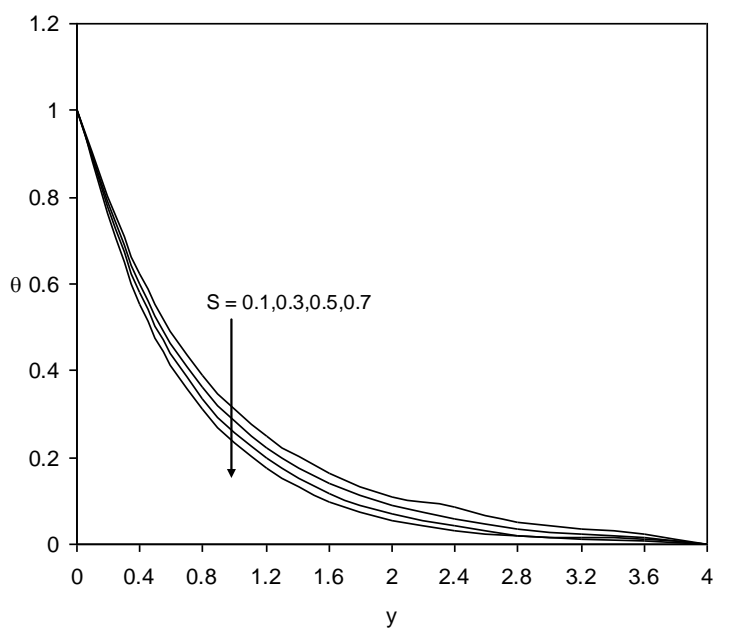

Fig. 17 : Variation of $\theta$ with $S$ $\mathrm{Q}_{1}=0.5$

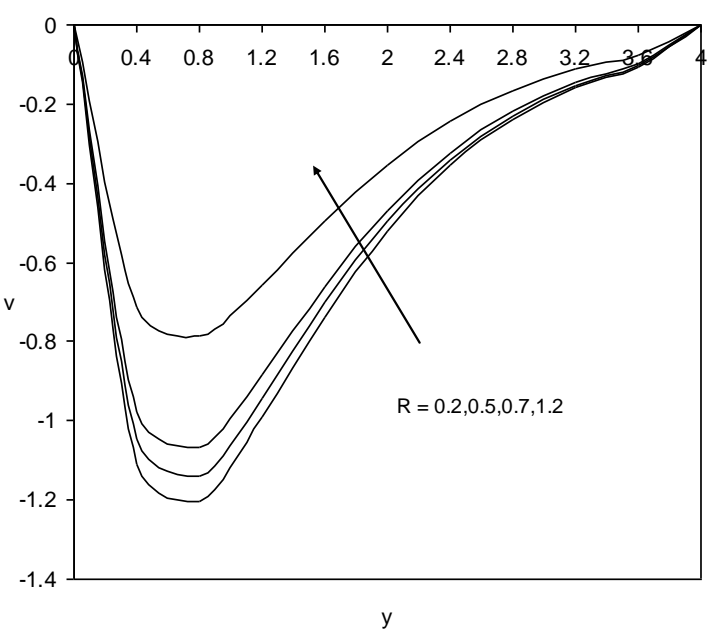

Fig. 14 : Variation of $\mathrm{v}$ with $\mathrm{R}$

$\mathrm{M}=2, \mathrm{~m}=0.5, \mathrm{Q}=0.5, \mathrm{~S}=0.5, \mathrm{~N}=1, \lambda=0.2, \mathrm{~N} 1=0.5$

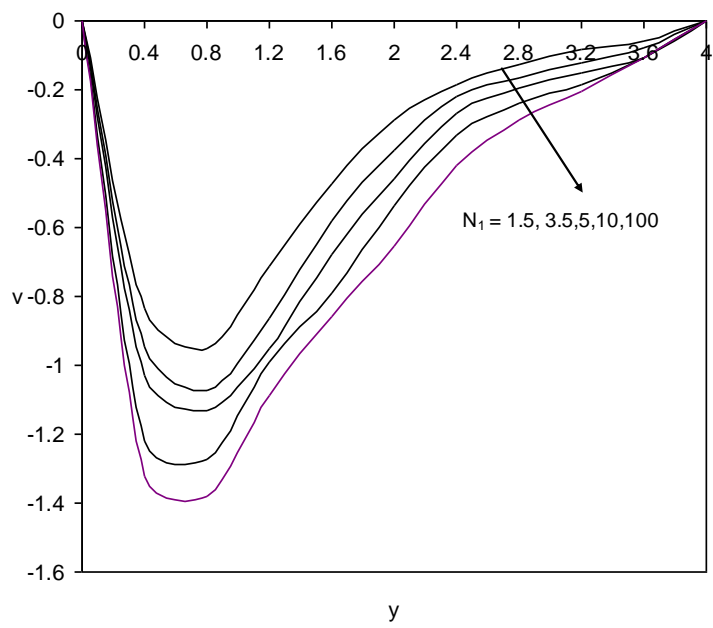

Fig. 16 : Variation of $\mathrm{v}$ with $\mathrm{N}_{1}$ $\mathrm{M}=2, \mathrm{~m}=0.5, \mathrm{Q}_{1}=0.5, \mathrm{~S}=0.5$, $\mathrm{R}=0.2, \mathrm{~N}=1, \lambda=0.2$

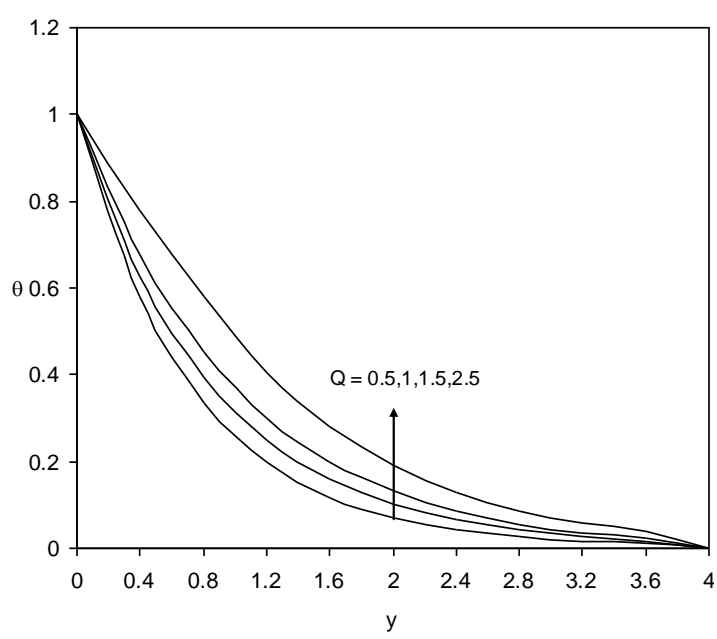

Fig. 18 : Variation of $\theta$ with $\mathrm{Q}_{1}$ $\mathrm{S}=0.5$ 
DOI: https://dx.doi.org/10.26808/rs.ca.i8v1.05 International Journal of Computer Application (2250-1797)

Issue 8 Volume 1, January- February 2018

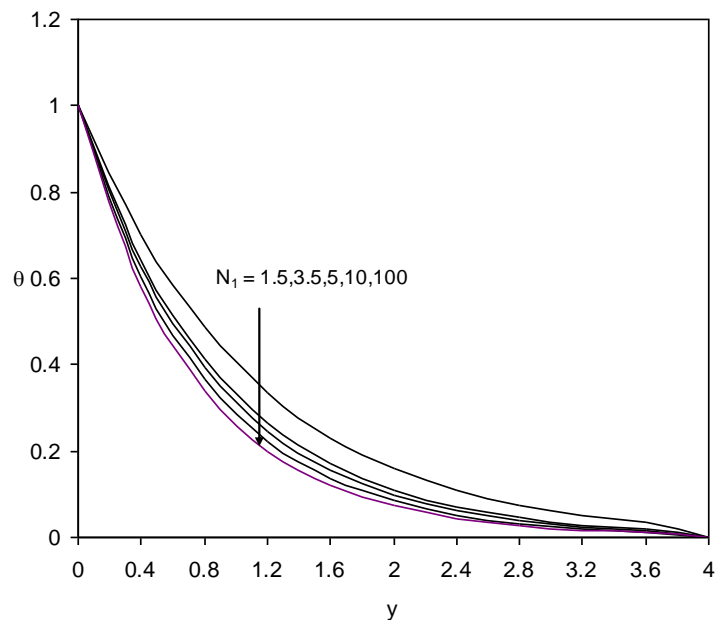

Fig. 19 : Variation of $\theta$ with $\mathrm{N}_{1}$ $\mathrm{Sc}=1.3$

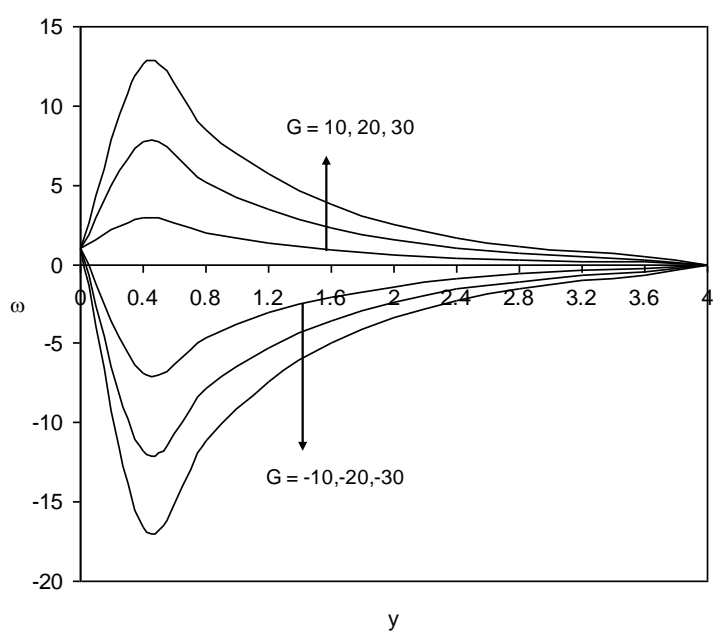

Fig. 21 : Variation of $\omega$ with $\mathrm{G}$ $\mathrm{M}=2, \mathrm{~m}=0.5, \mathrm{Q}_{1}=0.5, \mathrm{~S}=0.5$, $\mathrm{R}=0.2, \mathrm{~N}=1, \mathrm{~N} 1=0.5$

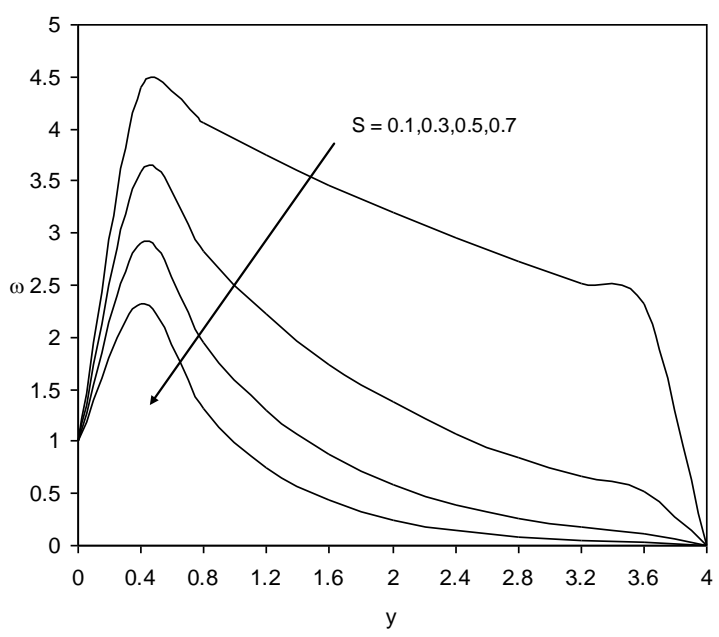

Fig. 23: Variation of $\omega$ with $\mathrm{S}$ $\mathrm{M}=2, \mathrm{~m}=0.5, \mathrm{Q}_{1}=0.5, \mathrm{~N} 1=0.5$ $\mathrm{R}=0.2, \mathrm{~N}=1$

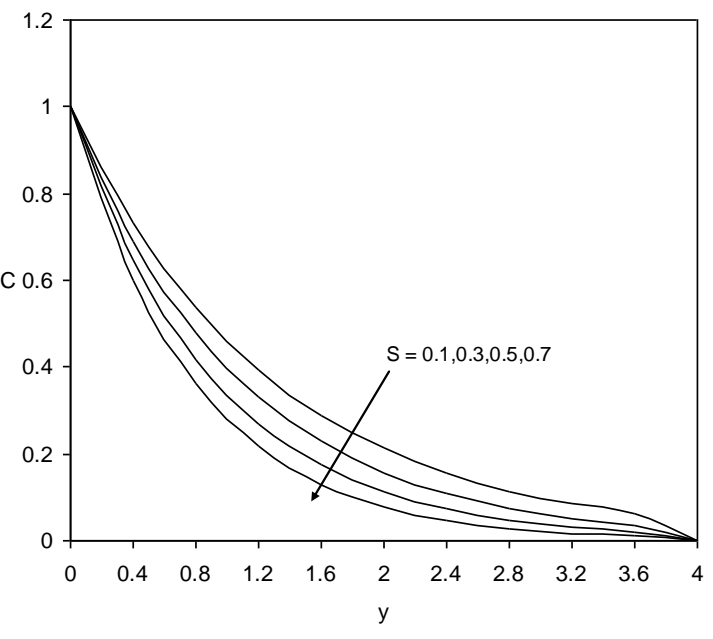

Fig. 20: Variation of C with $\mathrm{S}$

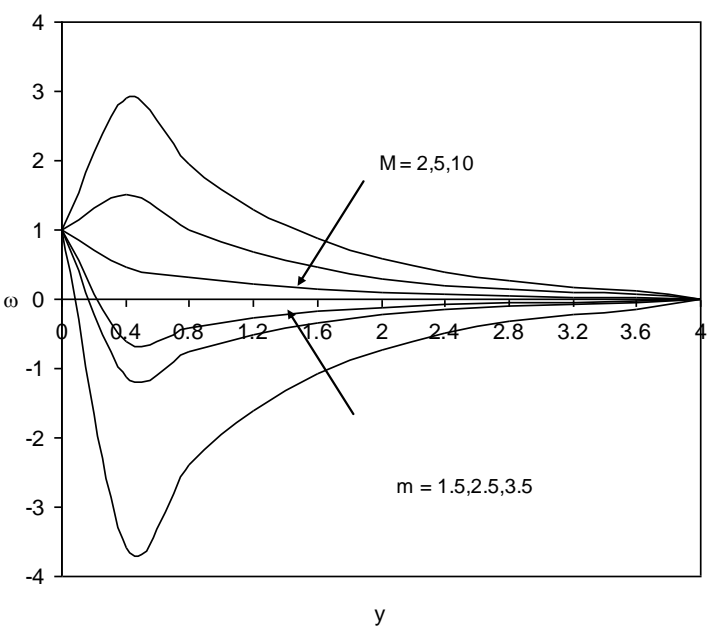

Fig. 22 : Variation of $\omega$ with $M \& m$ $\mathrm{Q}_{1}=0.5, \mathrm{~S}=0.5, \mathrm{R}=0.2, \mathrm{~N}=1, \mathrm{~N} 1=0.5$

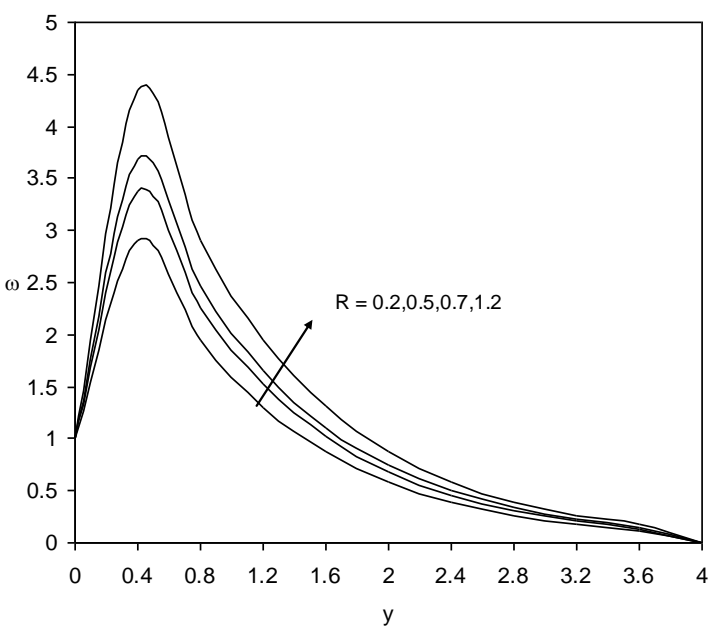

Fig. 24 : Variation of $\mathrm{v}$ with $\mathrm{R}$ $\mathrm{M}=2, \mathrm{~m}=0.5, \mathrm{Q}_{1}=0.5, \mathrm{~S}=0.5, \mathrm{~N}=1, \mathrm{~N} 1=0$. 

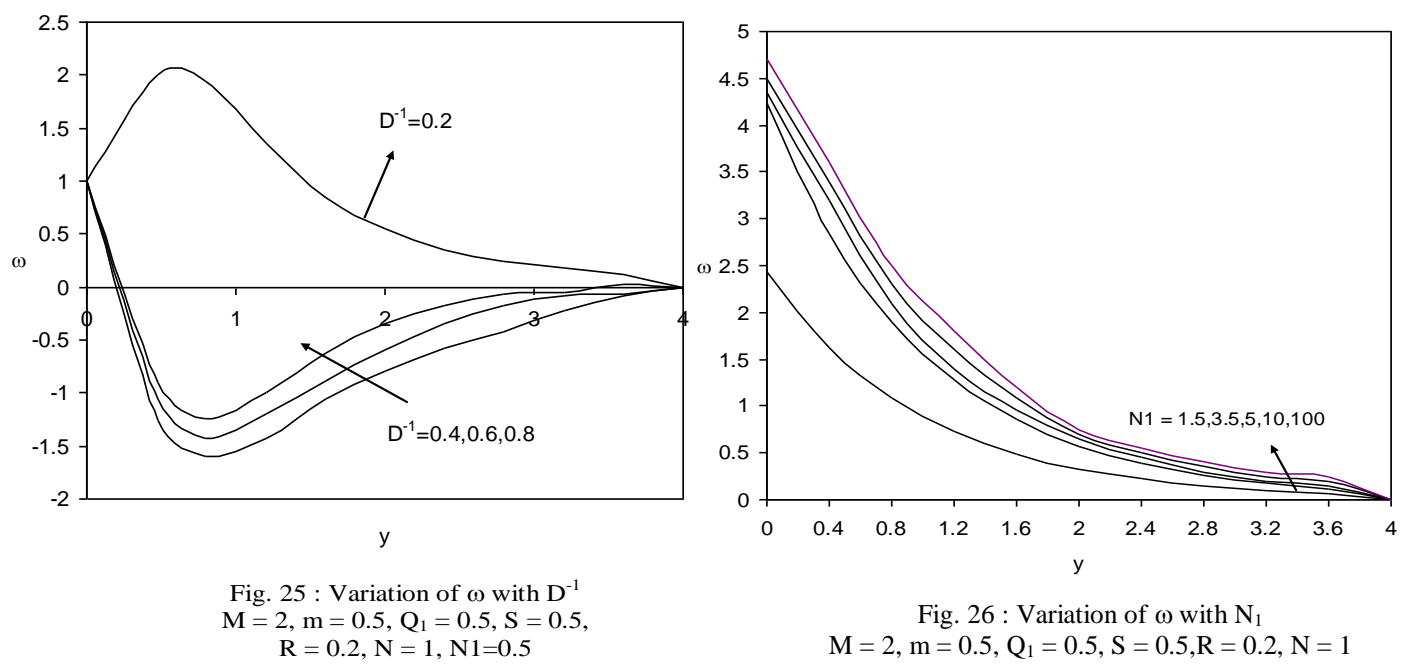
$=2, \mathrm{~m}=0.5, \mathrm{Q}_{1}=0.5, \mathrm{~S}=0.5$
$\mathrm{R}=0.2, \mathrm{~N}=1, \mathrm{~N} 1=0.5$

Fig. 26 : Variation of $\omega$ with $\mathrm{N}_{1}$ $\mathrm{M}=2, \mathrm{~m}=0.5, \mathrm{Q}_{1}=0.5, \mathrm{~S}=0.5, \mathrm{R}=0.2, \mathrm{~N}=1$

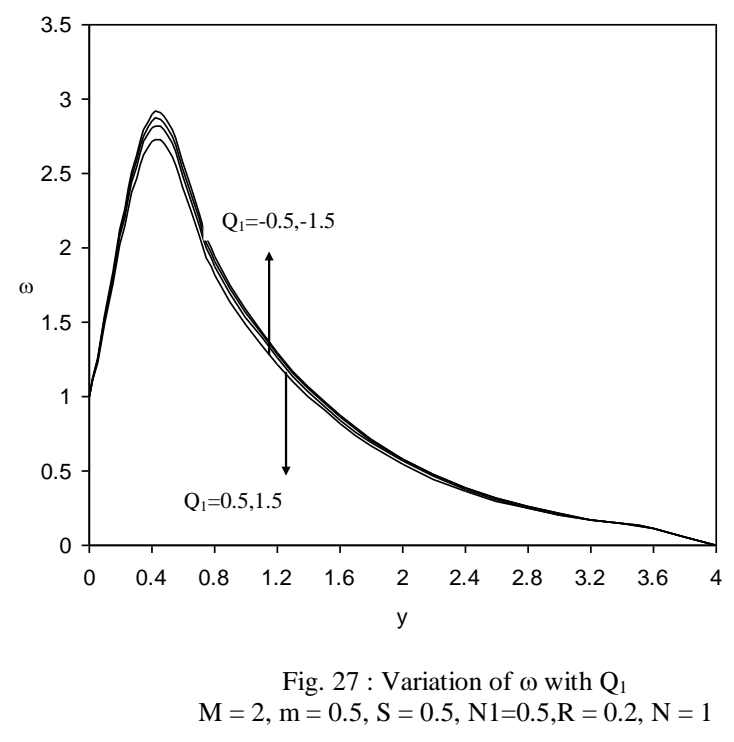

The skin friction $(\tau)$ at the boundary $y=0$ is represented in Tables (1-3) for different parametric values. It can be seen from the tabular values that the skin friction increases with increase in $G$ and reduces with $\mathrm{M}$ and $\mathrm{m}$. When the molecular buoyancy force dominates over the thermal buoyancy force the skin friction increases when the buoyancy forces are in the same direction and for the forces acting in opposite directions, it reduces on the boundary. An increase in the radiation absorption parameter $\mathrm{Q}_{1}$ leads to an enhancement in the skin friction at the wall. We find that the magnitude of skin friction reduces with increasing with radiation parameter (N1). We find that the skin friction increases with increase in $\mathrm{n}$ the suction parameter $\mathrm{S}$, heat source parameter $\alpha$ and rotation parameter $\mathrm{R}$.

The Couple stress $(\mathrm{Cw})$ at $\mathrm{y}=0$ is shown in Tables (4-6) for different parametric values. From Table.6, we find that the couple stress increases with $G$ and reduces with $M$ and $\mathrm{m}$. When the molecular buoyancy force dominates over the thermal buoyancy force the couple stress enhances in heating case and reduces in the cooling case when the buoyancy forces are in the same direction and for the forces acting in opposite directions, it reduces on the wall. Lesser the molecular diffusivity larger the couple stress at the wall. An increase in $\mathrm{Q}_{1}$ leads to an enhancement in couple stress at the wall. We find that the couple stress increases at the wall with increase in $S$ and $R$.

The rate of heat transfer (Nusselt number) at $y=0$ is depicted in Table (7). An increase in the radiation absorption parameter $\mathrm{Q}_{1}$ results in an enhancement in $|\mathrm{Nu}|$ at the plate. Also higher the strength of the heat source $\alpha$ and suction parameter $\mathrm{S}$ lead to an enhancement in $\mathrm{Nu}$ at the wall. The rate of heat transfer reduces with increasing radiation parameter N1 at wall. 
DOI: https://dx.doi.org/10.26808/rs.ca.i8v1.05 International Journal of Computer Application (2250-1797) Issue 8 Volume 1, January- February 2018

The rate of mass transfer (Sherwood number) at the wall $\mathrm{y}=0$ is shown in Table.8, for different values of $\mathrm{S}$. An increase in the suction parameter $\mathrm{S}$ leads to an increment in Sh.

Table $1:$ Skin friction $(\tau)$ at $y=0$

\begin{tabular}{|c|c|c|c|c|c|c|c|c|c|}
\hline $\mathrm{G}$ & I & II & III & IV & V & VI & VII & VIII & IX \\
\hline $\begin{array}{l}1 \\
0\end{array}$ & -9.63188 & -2.15609 & -0.9755 & -10.6363 & -8.63315 & $\begin{array}{l}- \\
4.6191 \\
2\end{array}$ & $\begin{array}{l}- \\
11.5921 \\
9\end{array}$ & -9.59681 & -9.35205 \\
\hline $\begin{array}{l}2 \\
0\end{array}$ & $\begin{array}{l}- \\
21.7636 \\
9\end{array}$ & $\begin{array}{l}- \\
47.1715 \\
3\end{array}$ & $\begin{array}{l}- \\
1.8242 \\
2\end{array}$ & $\begin{array}{l}- \\
21.0944 \\
6\end{array}$ & $\begin{array}{l}- \\
17.0766 \\
1\end{array}$ & $\begin{array}{l}- \\
8.4936 \\
9\end{array}$ & $\begin{array}{l}- \\
24.1823 \\
4\end{array}$ & $\begin{array}{l}- \\
17.8073 \\
8\end{array}$ & $\begin{array}{l}- \\
18.0087 \\
6\end{array}$ \\
\hline $\begin{array}{l}- \\
1 \\
0\end{array}$ & $\begin{array}{l}10.5958 \\
9\end{array}$ & 2.04778 & $\begin{array}{l}- \\
0.8469 \\
3\end{array}$ & $\begin{array}{l}10.7933 \\
4\end{array}$ & 8.83641 & $\begin{array}{l}4.8339 \\
8\end{array}$ & $\begin{array}{l}11.7755 \\
4\end{array}$ & 9.75088 & 9.50481 \\
\hline $\begin{array}{l}- \\
2 \\
0\end{array}$ & $\begin{array}{l}21.8061 \\
8\end{array}$ & 4.01459 & 1.1784 & $\begin{array}{l}21.5450 \\
5\end{array}$ & $\begin{array}{l}17.8312 \\
6\end{array}$ & $\begin{array}{l}9.0145 \\
9\end{array}$ & $\begin{array}{l}22.4276 \\
1\end{array}$ & $\begin{array}{l}18.2960 \\
4\end{array}$ & $\begin{array}{l}18.1681 \\
6\end{array}$ \\
\hline $\mathrm{M}$ & 2 & 4 & 6 & 2 & 2 & 2 & 2 & 2 & 2 \\
\hline $\mathrm{m}$ & 0.5 & 0.5 & 0.5 & 1.5 & 2.5 & 3.5 & 0.5 & 0.5 & 0.5 \\
\hline $\mathrm{N}$ & 1 & 1 & 1 & 1 & 1 & 1 & 2 & -0.5 & -0.8 \\
\hline
\end{tabular}

Table 2 : Skin friction $(\tau)$ at $y=0$

\begin{tabular}{|l|l|l|l|l|l|l|}
\hline $\mathrm{G}$ & \multicolumn{1}{|c|}{$\mathrm{I}$} & $\mathrm{II}$ & \multicolumn{1}{c|}{ III } & IV & V & VI \\
\hline 10 & -6.12751 & -13.83798 & -16.79728 & -9.13182 & -8.94208 & -7.64898 \\
\hline 20 & -11.81354 & -25.43475 & -16.22681 & -20.6424 & -19.6484 & -18.9818 \\
\hline-10 & 6.20884 & 13.9793 & 16.95167 & 9.4954 & 8.4814 & 8.0128 \\
\hline-20 & 12.8155 & 39.08068 & 15.3504 & 20.1482 & 19.1428 & 18.0498 \\
\hline $\mathrm{Q}_{1}$ & 0.5 & 1.5 & 2.5 & 0.5 & 0.5 & 0.5 \\
\hline $\mathrm{N}_{1}$ & 0.5 & 0.5 & 0.5 & 1.5 & 3.5 & 5 \\
\hline
\end{tabular}

Table 3 : Skin friction $(\tau)$ at $y=0$

\begin{tabular}{|l|l|l|l|l|l|c|c|}
\hline $\mathrm{G}$ & \multicolumn{1}{|c|}{$\mathrm{I}$} & $\mathrm{II}$ & $\mathrm{III}$ & $\mathrm{IV}$ & $\mathrm{V}$ & $\mathrm{VI}$ & VII \\
\hline 10 & -6.40382 & -7.95628 & -9.63188 & -10.7216 & -10.407 & -10.57242 & -10.76725 \\
\hline 20 & -12.89223 & -15.63948 & -21.76369 & -25.62885 & -19.61121 & -20.74498 & -21.31165 \\
\hline-10 & 6.34104 & 7.90443 & 10.59589 & 10.81732 & 10.64135 & 10.8957 & 11.14217 \\
\hline-20 & 12.92974 & 15.32665 & 21.80618 & 20.74302 & 19.45381 & 20.99508 & 21.77881 \\
\hline $\mathrm{S}$ & 0.1 & 0.3 & 0.5 & 0.9 & 0.5 & 0.5 & 0.5 \\
\hline $\mathrm{R}$ & 0.2 & 0.2 & 0.2 & 0.2 & 0.5 & 0.9 & 1.2 \\
\hline
\end{tabular}

Table 4 : Couple stress $(\mathrm{CW})$ at $\mathrm{y}=0$

\begin{tabular}{|l|c|c|c|c|c|c|c|c|c|}
\hline $\mathrm{G}$ & $\mathrm{I}$ & $\mathrm{II}$ & $\mathrm{III}$ & $\mathrm{IV}$ & $\mathrm{V}$ & $\mathrm{VI}$ & $\mathrm{VII}$ & $\mathrm{VIII}$ & $\mathrm{IX}$ \\
\hline 10 & 3.583 & 2.08729 & 2.00187 & 1.99606 & 1.9633 & 1.68367 & 2.7164 & 2.25826 & 2.25813 \\
\hline 20 & 3.61129 & 2.17097 & 2.06272 & 2.56527 & 2.29574 & 1.97621 & 1.71699 & 4.25913 & 3.49537 \\
\hline-10 & 1.11212 & 1.96529 & 2.04287 & 1.68858 & 1.79782 & 2.09964 & 1.52746 & 1.53405 & 1.53368 \\
\hline-20 & 1.19371 & 1.90924 & 2.00804 & 1.20623 & 1.29629 & -2.62158 & 1.44523 & 0.63922 & 0.36944 \\
\hline $\mathrm{M}$ & 2 & 4 & 6 & 2 & 2 & 2 & 2 & 2 & 2 \\
\hline $\mathrm{m}$ & 0.5 & 0.5 & 0.5 & 1.5 & 2.5 & 3.5 & 0.5 & 0.5 & 0.5 \\
\hline $\mathrm{N}$ & 1 & 1 & 1 & 1 & 1 & 1 & 2 & -0.5 & -0.8 \\
\hline
\end{tabular}


Table 5 : Couple stress $(\mathrm{CW})$ at $\mathrm{y}=0$

\begin{tabular}{|l|c|c|c|c|c|c|c|c|c|}
\hline $\mathrm{G}$ & $\mathrm{I}$ & $\mathrm{II}$ & $\mathrm{III}$ & $\mathrm{IV}$ & $\mathrm{V}$ & $\mathrm{VI}$ & $\mathrm{VII}$ & $\mathrm{VIII}$ & $\mathrm{IX}$ \\
\hline 10 & 0.32704 & 1.17303 & 3.583 & 3.07615 & 6.73697 & 11.21963 & 2.2563 & 2.26337 & 2.74617 \\
\hline 20 & 0.2529 & 1.69565 & 2.61129 & 2.61632 & 4.21181 & 20.35635 & 1.62507 & 3.30033 & 3.33313 \\
\hline-10 & 0.19476 & 0.72832 & 1.11212 & 2.40722 & 2.05442 & 2.57337 & 1.48826 & 1.638787 & 1.81521 \\
\hline-20 & 0.57518 & 0.66578 & 1.14371 & 2.67011 & 16.78273 & -18.71379 & 0.76044 & 2.33165 & 2.64337 \\
\hline $\mathrm{S}$ & 0.1 & 0.3 & 0.5 & 0.9 & 0.5 & 0.5 & 0.5 & 0.5 & 0.5 \\
\hline $\mathrm{Q}_{1}$ & 0.5 & 0.5 & 0.5 & 0.5 & 1.5 & 2.5 & 0.5 & 0.5 & 0.5 \\
\hline $\mathrm{R}$ & 0.2 & 0.2 & 0.2 & 0.2 & 0.2 & 0.2 & 0.5 & 0.9 & 1.2 \\
\hline
\end{tabular}

Table 6 : Couple stress $(\mathrm{CW})$ at $\mathrm{y}=0$

\begin{tabular}{|l|c|l|l|l|}
\hline $\mathrm{G}$ & \multicolumn{1}{|c|}{ I } & \multicolumn{1}{c|}{ II } & \multicolumn{1}{c|}{ III } & IV \\
\hline 10 & 2.19596 & 2.63464 & 2.94084 & 3.1089 \\
\hline 20 & 3.23458 & 3.3549 & 3.6488 & 3.9848 \\
\hline-10 & 1.31091 & 1.45121 & 1.64856 & 1.9849 \\
\hline-20 & 1.04366 & 1.09152 & 1.15184 & 1.20152 \\
\hline $\mathrm{N}_{1}$ & 0.5 & 1.5 & 3.5 & 5 \\
\hline
\end{tabular}

Table 7 : Nusselt Number $(\mathrm{Nu})$ at $\mathrm{y}=0$

\begin{tabular}{|l|l|l|l|l|l|l|l|l|l|}
\hline $\mathrm{G}$ & \multicolumn{1}{|c|}{ I } & \multicolumn{1}{c|}{ II } & \multicolumn{1}{c|}{ III } & \multicolumn{1}{c|}{ IV } & \multicolumn{1}{c|}{ V } & \multicolumn{1}{c|}{ VI } & \multicolumn{1}{c|}{ VII } & \multicolumn{1}{c|}{ VIII } & \multicolumn{1}{c|}{ IX } \\
\hline 0.24 & - & - & - & - & - & - & - & -1.6526 & - \\
& 1.89626 & 2.37927 & 2.86226 & 1.80511 & 1.99499 & 2.10065 & 1.73462 & & 1.49854 \\
\hline 0.6 & - & - & - & - & - & - & - & -1.7512 & - \\
& 1.97285 & 2.55413 & 3.13540 & 1.84848 & 2.10971 & 2.25969 & 1.85124 & & 1.62254 \\
\hline 1.3 & - & - & - & - & - & - & -2.0289 & -1.9848 & - \\
& 2.20882 & 3.12052 & 4.03222 & 1.95838 & 2.55027 & 3.06436 & & & 1.84289 \\
\hline 2.01 & - & - & - & - & 3.93403 & - & - & - & - \\
& 2.99287 & 5.24987 & 7.50686 & 2.15126 & & 1.43995 & 2.74124 & 2.54098 & 2.40988 \\
\hline $\mathrm{Q}_{1}$ & 0.5 & 1.5 & 2.5 & 0.5 & 0.5 & 0.5 & 0.5 & 0.5 & 0.5 \\
\hline $\mathrm{S}$ & 0.5 & 0.5 & 0.5 & 0.3 & 0.7 & 0.9 & 0.5 & 0.5 & 0.5 \\
\hline $\mathrm{N}_{1}$ & 0.5 & 0.5 & 0.5 & 0.5 & 0.5 & 0.5 & 1.5 & 3.5 & 5 \\
\hline
\end{tabular}

Table $8:$ Sherwood Number $(\mathrm{Sh})$ at $\mathrm{y}=0$

\begin{tabular}{|l|c|c|c|c|}
\hline $\mathrm{G}$ & I & II & III & IV \\
\hline 0.24 & -0.78722 & -0.83017 & -0.88375 & -0.94433 \\
\hline 0.6 & -0.84241 & -0.92353 & -1.01381 & -1.11225 \\
\hline 1.3 & -0.95945 & -1.12933 & -1.31507 & -1.51389 \\
\hline 2.01 & -1.10755 & -1.41219 & -1.74885 & -2.10731 \\
\hline $\mathrm{S}$ & 0.3 & 0.5 & 0.7 & 0.9 \\
\hline
\end{tabular}

\section{CONCLUSIONS}

An increasing in $G$, enhance primary velocity $(\mathrm{u})$, secondary velocity $(\mathrm{v})$ and microrotation $(\omega)$, skin friction $(\tau)$, couple stress $(\mathrm{Cw})$ increases with $\mathrm{G}$.

$>$ An increasing rotation parameter $(\mathrm{R})$, enhances the primary velocity $(\mathrm{u})$, microrotation $(\omega)$, skin friction $(\tau)$ and couple stress while the secondary velocity $(\mathrm{v})$ reduces in magnitude 
$>$ An increasing $\mathrm{M}$ reduces the primary velocity $(\mathrm{u})$ and microrotation $(\omega)$ and enhances secondary velocity $(v)$, skin friction $(\tau)$ and couple stress $(\mathrm{Cw})$ reduces with $\mathrm{M}$.

$>$ An increasing inverse Darcy parameter $\left(\mathrm{D}^{-1}\right)$ reduces with velocity components and microrotation $(\omega)$.

$>$ An increasing Hall parameter $(\mathrm{m})$ enhances in the primary velocity $(\mathrm{u})$ and reduces secondary velocity $(v)$, microrotation $(\omega)$, skin friction $(\tau)$ and couple stress $(\mathrm{Cw})$ reduces with increase in Hall parameter $(\mathrm{m})$.

$>$ The velocity components reduces with increasing buoyancy ratio $(\mathrm{N})$ and enhances with increase in $|\mathrm{Nu}|$ lesser the molecular diffusivity smaller the velocity components, microrotation $(\omega)$, concentration $(\mathrm{C})$ and skin friction $(\tau)$ and enhance the rate of heat and mass transfer.

$>$ An increasing heat source parameter $(\alpha)$, enhances the primary velocity $(u)$, microrotation $(\omega)$, temperature $(\theta)$, skin friction $(\tau)$ and Nusselt number $(\mathrm{Nu})$ and reduces the primary velocity $(u)$ higher the radiative heat flux larger the velocity components, temperature $(\theta)$, skin friction $(\tau)$ and Nusselt number $(\mathrm{Nu})$.

$>$ An increasing chemical reaction parameter $(\mathrm{k})$, reduces the velocity components, microrotation $(\omega)$, skin friction $(\tau)$ and enhances couple stress $(\mathrm{Cw})$, rate of heat and mass transfer.

$>$ An increasing radiation absorption parameter $(\mathrm{Q})$, enhances primary velocity $(\mathrm{u})$, secondary velocity $(\mathrm{v})$, skin friction $(\tau)$, couple stress $(\mathrm{cw})$ and nusselt number $(\mathrm{Nu})$ and reduces $\mathrm{u}$ and microrotation $(\omega)$.

\section{REFERENCES}

[1] Alfven, H : Discovery of Alfven waves. Nature, 150, p.405 (1942).

[2] Bakr, A.A: Effects of chemical reaction on MHD free convection and mass transfer flow of a micropolar fluid with oscillatory plate velocity and constant heat source in a rotating frame of reference, Commun. Non linear Sci. Numer. Simul. 16, pp.698-710 (2011).

[3] Cogley, A.C., Vincenty, W.E. and Gilles, S.E : Differential approximation for radiation in a non-gray gas near equilibrium, AIAA J. 6, pp.551-553 (1968).

[4] Crammer, K.P. and Pai, S.L : Magneto-fluid dynamics for Engineers and applied physics. Mc-Graw Hill Book Co. New York (1978).

[5] Das, K : Effect of chemical reaction and thermal radiation on heat and mass transfer flow of MHD micropolar fluid in a rotating frame of reference, Int. Heat and Mass Transfer, V. 54, pp.3505-3513 (2011).

[6] El-Arabawy, H.A.M : Effect of suction/infection on the flow of a micropolar fluid past continuously moving plate in the presence of radiation, Int. J. Heat and Mass Transfer, Vol. 46, pp. 471-477 (2003).

[7] Eringen, A.C : Theory of thermo micro fluids. Math. Anal. Appl., Vol. 38, pp. 480-496 (1972).

[8] Eringen, A.C : Theory of micropolar fluids, J. Math. Mech. 16, pp. 1-18 (1964).

[9] Ferraro, V.C.A and Plumpton, C : An introduction to magneto fluid mechanics, Clarande press, Oxford (1966).

[10] Greenspan,H.P ( 1968): The theory of Rotating fluids, Cambridge University press, Cambridge (1968).

[11] Gibben, R.J : The magneto hydrodynamic boundary layer in the presence of a pressure gradient, Proc. Soc. Vol. 287 (A), pp.123-141(1965).

[12] Hayat, T., Khan S.B. and Khan M : The influence of Hall current on the rotating oscillating flows of a fluid in a porous medium, on linear dynamics, V. 47, pp. 353-362 (2007) .

[13] Ibrahim, F.S., Elaiw, A.M. and Bakr, A.A : Influence of viscous dissipation and radiation on unsteady MHD mixed convection flow of micropolar fluids, Appl. Math. Inf. Sci. 2, pp.143162 (2008). 
[14] Ibrahim, F.S., Elaiw, A.M. and Bakr, A.A : Effect of the chemical reaction and radiation absorption on unsteady MHD mixed convection flow past a semi-infinite vertical permeable moving plate with heat source and suction, Commun. Nonlinear Sci. Numer. Simul. 13, pp.1056-1066 (2008) .

[15] Khonsari, M.M. and Brewe, D.E : Effects of viscous dissipation on the lubrication characteristics of micropolar fluids, Acta Mech. 105, pp.57-68 (1994).

[16] Kim, Y.J. and Lee, J.C : Analytical studies on MHD oscillatory flow of a micropolar fluid over a vertical plate, surface and Coatings Technology, Vol. 171, pp. 187-193 (2003).

[17] Kim, Y.J : MHD micropolar fluid flow past a vertical moving plate. Vertical moving plate in a porous medium, TransPorous Media, 56, pp.17-37 (2004)

[18] Muthu, P., Rathish Kumar, B.V. and Peeyush Chandra : Peristaltic motion of micropolar fluid in circular cylindrical tubes: Effect of wall properties, Applied Mathematical Modeling, 32,pp. 2019-2033 (2008)

[19] Muthuraj, R. and Srinivas, S : Heat and mass transfer in MHD micropolar flow over a Fully developed MHD flow of a micropolar and viscous fluids in a vertical porous space using HAM, Int. J. of Appl. Math and Mech. 6, pp.55-78 (2010).

[20] Radhakrishnamachary, G.A : Flow of Micropolar Fluid through a Constricted Channel, Int. J. Engg. Sci. 15, pp.179-185 (1977).

[21] Rahman, M.M. and Sattar M.A: MHD free convection and mass transfer flow with oscillatory plate velocity and constant heat source in a rotating frame of reference, Dhaka Univ. J. Sci. 47, pp.53-73 (1999)

[22] Rahman, M.M. and Sattar, M.A: Transient convective flow of micropolar fluid past a continuously moving vertical porous plate in the presence of radiation, Int. J. Appl. Mech. Eng. 12, pp. 497-513 (2007)

[23] Rahman, M.M : Convective flows of micropolar fluids from radiate isothermal porous surfaces with viscous dissipation and Joule heating, Commun. Non linear Sci. Numer. Simul. 14, pp.3018-3030 (2009)

[24] Rapits, A: Flow of a micropolar fluid past a continuously moving plate by the presence of radiation, Int. J. Heat Mass Transfer, Vol. 41, pp. 2865-2866 (1998).

[25] Rees, D. and Pop, I: Free convection boundary-layer flow of a micropolar fluid from a vertical flat plate, IMA Journal of Applied Mathematics, 61, pp.179-197 (1998)

[26] Satyanarayana, P.V., Venkateswarulu, B. and Venkataramana, S : Effects of Hall current and radiation absorption on MUD micro polar fluid in a rotating system, ASEJ, Vol 4(4), pp.843-854 (2013) .

[27] Seddeek, M.A : Flow of a maganeto-micro polar fluid past a continuousely moving plate, Elsevier, sciencedirect.com, physics letters A, 306, pp.255-257 (2003)

[28] Shercliff, J.A: A text book of magneto hydrodynamics, pergamon press, London (1965) .

[29] Sharma, R.C. and Gupta, U : Thermal convection in micropolar fluids in porous medium, Int. J. Eng. Sci. 33, pp.1887-1892 (1995)

[30] Srinivasacharya, D., Ramanamurthy, J.V. and Venugopalam, D : Unsteady Stokes flow of micropolar fluid between two parallel porous plates, Int. J. Engg. Sci. 39, pp. 1557-1563 (2001)

[31] Sulochana, C., Ganana prasunamba, K (2013): Effect of Hall current and radiation absorption on chemically flow of Magnatic field in rotating fluid past a vertical porous plate, IJMA, Vol 4(11), pp.1-16 (2013)

[32] Suresh, V., Rajeswara Rao, U and Prasada Rao, D.R.V : Effect of thermo diffusion and chemical reaction on convective heat and mass transfer flow of rotating micro polar fluid with Hall effect past a vertical plate. IJASTR, Vol 3(4), pp.585-597 (2014). 